\title{
Three-dimensional structures of Lipoproteins from Streptococcus pneumoniae and Staphylococcus aureus
}

\author{
Sergio G. Bartual ${ }^{1}$, Martín Alcorlo, Siseth Martínez-Caballero, Rafael Molina, Juan A. Hermoso* \\ Department of Crystallography and Structural Biology, Institute of Physical Chemistry "Rocasolano", CSIC, 28006 Madrid, Spain
}

\section{A R T I C L E I N F O}

\section{Keywords:}

Streptococcus pneumoniae

Staphylococcus aureus

Lipoproteins

Protein structure

Virulence

\begin{abstract}
A B S T R A C T
Bacterial lipoproteins (Lpp) compose a large family of surface-exposed proteins that are involved in diverse, but critical, cellular functions spanning from fitness to virulence. All of them present a common signature, a sequence motif, known as LipoBox, containing an invariant Cys residue that allows the protein to be covalently bound to the membrane through a thioether linkage. Despite the abundance and relevance of Lpp, there is a scarcity of structural and functional information for this family of proteins. In this review, the updated structural and functional data for Lpp from two Gram-positive pathogenic model organisms, Staphylococcus aureus and Streptococcus pneumoniae is presented. The available structural information offers a glimpse over the Lpp functional mechanisms. Their relevance in bacterial fitness, and also in virulence and host-pathogen interactions, reveals lipoproteins as very attractive targets for designing of novel antimicrobials, and interesting candidates as novel vaccine antigens.
\end{abstract}

\section{Introduction}

A common feature of all bacterial groups is the presence of a single or double membrane that serves, among other functions, as an anchor point for proteins. Membrane proteins can be classified according to their interaction with the membrane as integral membrane proteins, when they are embedded in the phospholipid bilayer by transmembrane segments, or peripheral membrane proteins, when they remain attached to the membrane surface but not inserted. Bacterial lipoproteins (Lpp) are classified as peripheral membrane proteins that have been shown to be directly involved in diverse, but critical, cellular functions like: cell fitness, division, signal transduction, motility, redox and antibiotic resistance, extracytoplasmic folding of proteins, conjugation, sporulation, adhesion and virulence (Abdullah et al., 2014; Alloing et al., 1994; Kohler et al., 2016; Nguyen and Gotz, 2016; Saleh et al., 2013; Schmaler et al., 2009; Shahmirzadi et al., 2016) (Fig. 1A). Indeed, Lpp contribute directly to the pathogen virulence by promoting colonization, invasion, and survival in the host bloodstream (KovacsSimon et al., 2011; Pribyl et al., 2014; Saleh et al., 2013).

Gram-negative Lpp could be placed in any of the two membranes but normally are attached to the inner leaflet of the outer membrane (Narita et al., 2004). In Gram-positive bacteria Lpp are translocated from the inner face of the plasma membrane to the extracellular surface (Hutchings et al., 2009). Furthermore, due to the lack of a second membrane, Gram-positive bacteria avoid the diffusion of many vital proteins into the external space by turning them into Lpp.

Bacterial Lpp modification, normally, includes the attachment of an $\mathrm{N}$-Acyl Diacyl Glycerol group that allows Lpp to remain attached to the membranes by direct interaction with the phospholipids polar heads. Some Gram-positive bacteria like $S$. aureus can, in addition to the NDiacyl Glycerol, attach N-Acyl Triacyl Glycerol depending on environmental conditions (Nakayama et al., 2012). Lpp typically consist of an $\mathrm{N}$-terminus signal peptide, containing positively-charged residues, a hydrophobic sequence and the LipoBox motif [LVI] [ASTVI] [GAS] [C] (Sankaran and Wu, 1994) (Fig. 1B). After synthesis, the N-terminal signal peptide allows preprolipoproteins to be translocated across the cytoplasmic membrane by either a Sec or Tat secretory pathways (Driessen and Nouwen, 2008). Then is anchored to the cell wall by the addition of diacylglyceryl moieties (lipidation) to the thiol group of an invariant cysteine residue in the lipobox motif via the lipoprotein diacylglyceryl transferase (Ltg) (Kohler et al., 2016; Oudega et al., 1993). Finally, a type II signal peptidase (Lps) cleaves the N-terminal signal peptide close to the Cys/diglyceride bond generating the mature lipoprotein.

Interestingly, in many Gram-positive pathogenic bacteria, such as Streptococcus pneumoniae or Staphylococcus aureus, most Lpp are required for sustaining virulence in pathogen-host interactions (Johnston et al., 2004; Saleh et al., 2013; Shahmirzadi et al., 2016). However,

\footnotetext{
* Corresponding author.

E-mail address: xjuan@iqfr.csic.es (J.A. Hermoso).

${ }^{1}$ Present address: School of Life Sciences, University of Dundee, DD1 5HL, Dundee, UK.
} 

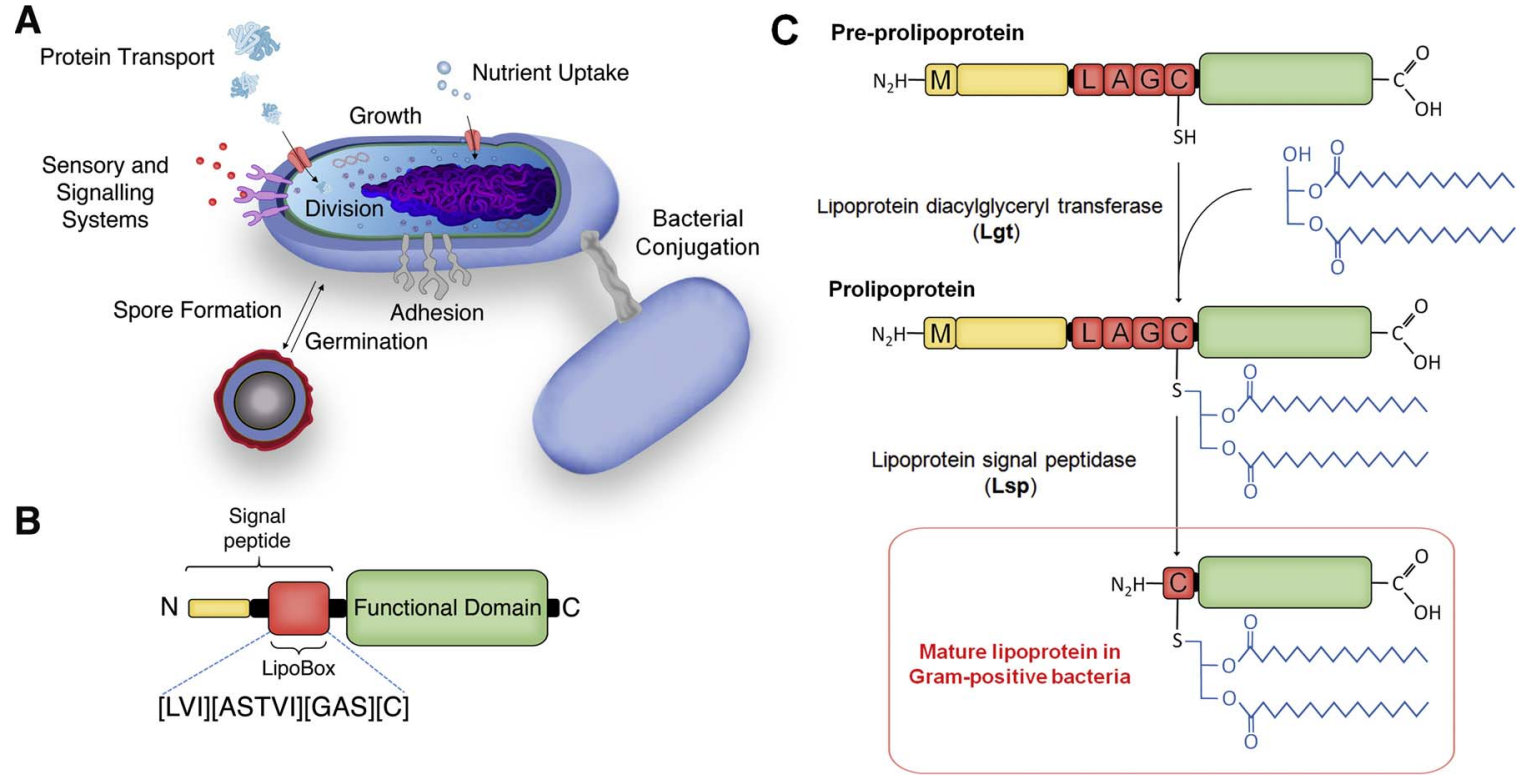

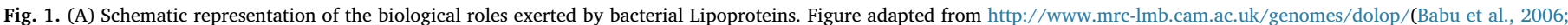

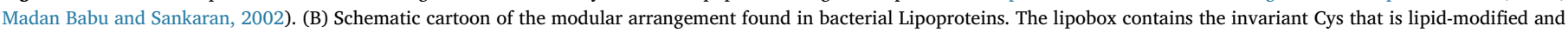

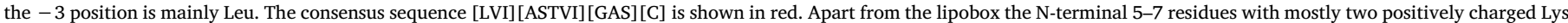

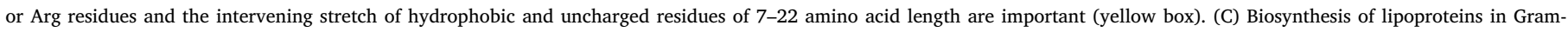

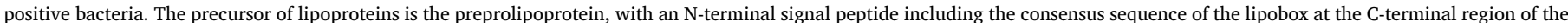

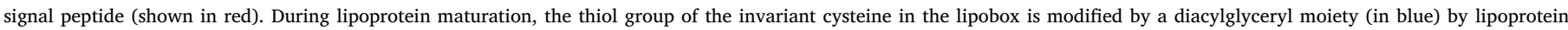

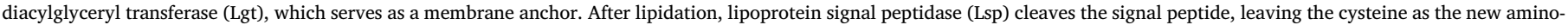

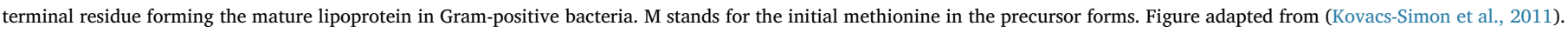
(For interpretation of the references to colour in this figure legend, the reader is referred to the web version of this article.)

despite their attractiveness as potential Gram-positive antimicrobial targets and novel vaccine antigens, little is known about their threedimensional structures. There are different facts that could explain the scarcity of structural information in Lpp family. Among them, the hydrophobic nature of the full-length protein (all the up to now reported crystal structures of Lpp are obtained after deletion of the LipoBox region), the usual presence of a flexible linker connecting the lipidated Cys with the functional domain(s) that hamper crystallization of Lpp, and finally, the insufficient information about in vivo functions for many of these Lpp (few of them presenting a catalytic activity), could explain why these proteins have been typically neglected in structural studies. I.e. within the disease model organisms $S$. aureus USA300 and Pneumococcus TIGR4, $83 \%$ and $49 \%$ of their respective Lpp remains structurally uncharacterized. Furthermore, among all the available Lpp structures only half of them have been functional and biochemically characterized. This fact reflects the huge gap in knowledge for this group of critical membrane proteins.

During the last years, there has been intensive bioinformatics analysis of bacterial Lpp. An example of this is the development of DOLOP, a knowledge base for bacterial lipoproteins (http://www.mrc-lmb.cam. ac.uk/genomes/dolop/) that provides a list of functional classification, predictive algorithm for query sequences, primary sequence analysis and lists of predicted lipoproteins from different completed bacterial genomes (Babu et al., 2006; Madan Babu and Sankaran, 2002). DOLOP, accessed on July 2017, contains information of 199 distinct lipoproteins identified among 43 bacterial genomes and classified according to their cellular functions. Although it is a powerful computational tool, DOLOP still doesn't offer functional or structural correlation to published data.

As all the reported three-dimensional structures of Lpp refer to the protein part, and typically just their functional domains, this review focus on the comparison of the Lpp roles and associated three-dimensional structures for two main Gram-positive human pathogens, $S$. pneumoniae TIGR4 and the $S$. aureus MRSA USA300.

\section{Overview of the solved $S$. pneumoniae and $S$. aureus lipoproteomes}

Lipoproteome constitutes a minimal fraction of the total bacterial genome, $1.76 \%$ in the case of $S$. pneumoniae TIGR4 and $2.04 \%$ for the bigger $S$. aureus complete genome (Babu et al., 2006). Due to their exposed location and the critical functions under their command, Lpp are being considered targets for the generation of new antimicrobials and interesting candidates for novel vaccine antigens. However, to achieve this goal a deep structural and functional knowledge is required.

Evaluation of the protein data bank (PDB, https://www.rcsb.org/ $\mathrm{pdb} /$ home/home.do) accessed on July 2017, reveals that, in the case of S. aureus USA300, only one third of lipoproteins have been, up to now, structurally characterized. PDB database contains only 18 out of a total of the 67 lipoproteins reported in the strain USA300 that accounts for $0.7 \%$ of the total genome (Shahmirzadi et al., 2016). Interestingly, among all the deposit bacterial Lpp structures, there is no structural information of the lipobox or the attached lipid, thus only Lpp catalytic protein cores can be structurally analysed. A large proportion of the staphylococcal Lpp is involved in the uptake of essential ions and nutrients, 24 Lpp are distributed among metal, anion, amino acid and sugar transporters (Fig. 2A). Of them, only 9 have been structurally determined: 4 iron transporters (FhuD2, SirA, SirF and HstA), one manganese and one nickel transporters (MntC and NikA, respectively), one nitrate $\mathrm{ABC}$ binding protein, two amino acid transporters (OpuCc and $\mathrm{GmpC}$ ) and one maltose binding protein (Table 1A). The rest of the $S$. aureus Lpp are divided into other 7 functional categories (Biosynthesis, Respiration, Protein folding, Protein translocation, Phage and plasmid Lpp, Lpl cluster and the unknown Lpp) that accounts for the $62.68 \%$ of the total lipoproteome. However, the structures of only $11 \%$ of them have been solved (Table 1A). The Biosynthesis category has a single Lpp involved in plasmid uptake whose structure is reported (CamS). Respiration category contains two Lpp but no structure is reported so far. The Protein folding category contains two Lpp of known 
A

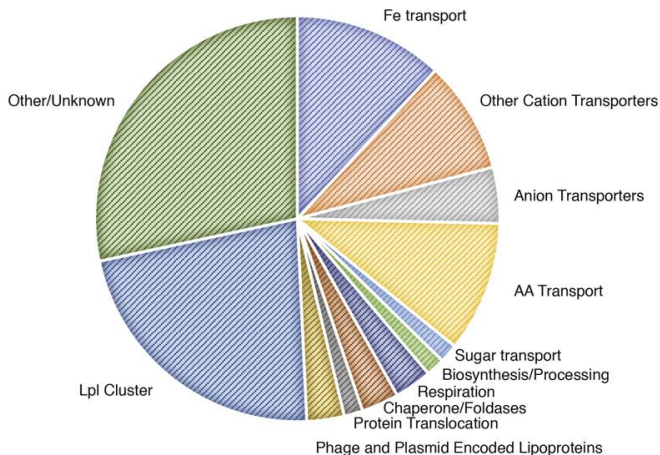

B

Streptococcus pneumoniae lipoproteins distribution

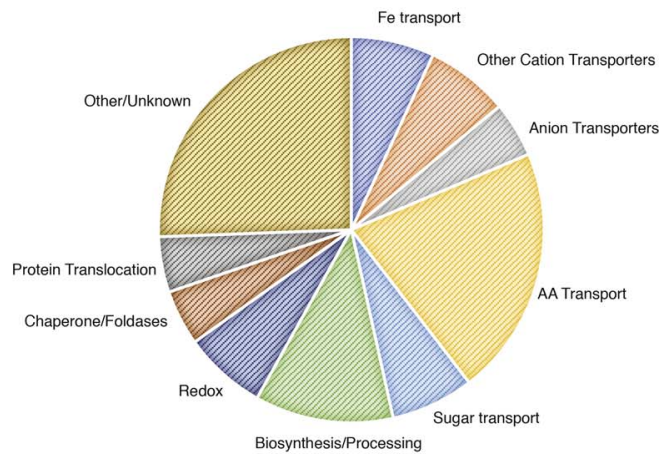

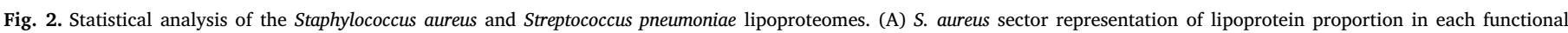

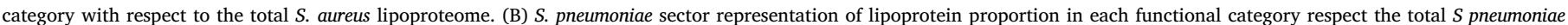
lipoproteome.

structure (PrsA and DsbA). No structural information has been reported for the only one Lpp (YidC) involved in translocation mechanisms. Two proteins have been classified into the Phage and Plasmid encoded Lpp (PhiSLT and BlaZ) being BlaZ the only structurally characterized (Chen and Herzberg, 2001). Furthermore, USA300 strain carries relatively high number of tandem repeated Lpp in the $\nu$ Saa genomic island $(22 \%$ of the total Lpp) (Nguyen et al., 2015a,b). Among them, nine homologous $l p p$, referred to as "lipoprotein-like" (lpl) play a role in pathogenicity and are encoded by the $\nu$ Sa $\alpha$ genomic island (Babu et al., 2006); however, their exact function is still unknown. Only two structures have been reported up to date (Csa 1A and Csa 1B). Finally, 28\% of the staphylococcal lipoproteome is classified as unknown. Two structures have been reported for this group, although biochemical validation is not yet available (Table $1 \mathrm{~A}$ ).

In contrast with the $S$. aureus USA300 case, approximately $50 \%$ of the $S$. pneumoniae TIGR4 lipoproteome is structurally characterized (20 out of $43 \mathrm{Lpp}$ ). Although, in general, pneumococcus has a significant less number of $\mathrm{ABC}$ transporters compared with an average $S$. aureus strain, the number of available structures among metal, cation, anion, amino acid and sugar ABC transporters is quite similar in both organisms; 10 in S. pneumoniae TIGR4 vs 9 in S. aureus USA300. Two, out of 3 iron transporters (PiaA and PiuA), a manganese (PsaA) and a Zinc binding protein (AdcAII) completes the picture of the structurally known metal transporters in pneumococci. It is worth to notice that although the structures of the two putative phosphate transporters Lpp (PstS1 and PstS2) have been solved, none of them has, up to date, any associated biochemical analysis. Four out of 9 amino acids transporters have been structurally characterized (AbpA, GlnH, AatB and LivJ) and finally, all the 5 sugar transporters (FcsSBP, RafE, MalX, NgtS and FusA) are available in the PDB (Table 1B). Due to its specific life style, $S$. pneumoniae TIGR4 has a functional cluster of Lpp dedicated to ROS (reactive oxygen species) resistance with 3 out of 3 redox proteins whose structure is known (Etrx1, Etrx2 and GshT). Furthermore, it is interesting to notice a higher number of biosynthetic Lpp in pneumococci; 5 Lpp compared with just one in $S$. aureus. Two out of $5 \mathrm{Lpp}$ in this biosynthetic category have solved structures (DacB and SP0198). Two chaperone Lpp are also present in $S$. pneumoniae and both have reported 3D structures (SrtD and PrsA). None of the protein translocation Lpp have reported structures so far. Finally, the 3D structures for 3 Lpp from the Unknown categories have been determined (Table 1B).

In this review, we have grouped the three-dimensional structures of Lpp according to their established, or predicted, function. Thus, Lpp are classified as substrate-binding proteins in $\mathrm{ABC}$ transporters (including Iron, Cation, Anion and Sugar transporters), redox and respiration proteins, biosynthetic and processing proteins, chaperon and foldase proteins, Lpp involved in protein translocation, miscellaneous (Lpl cluster of antigens, or $\nu \nu \mathrm{Sa} \alpha$ genomic island, and proteins from phage or plasmid origin) and, finally, the hotchpotch category of Unknown Lpp (Table 1).

\section{Three-dimensional structures of Lpp associated to ABC transporters}

$\mathrm{ABC}$ transporters function as protein complexes that are able to translocate specific substrates across the phospholipid bilayer of the cell membrane. All ABC transporters share a common protein complex architecture composed of two permease components, two nucleotide binding components (ATPases) and one specific cargo protein which in bacteria is often one Lpp substrate-binding protein (SBP) (Khandavilli et al., 2008). SBPs have a highly conserved three-dimensional structural fold, even though they often have little or no sequence similarity and can bind quite different types of substrates. They consist of two $\alpha / \beta$ domains, each of them with a central $\beta$-sheet core with 4-6 $\beta$-strands flanked by $\alpha$-helical periphery, and the substrate binds between the two domains.

Traditionally, the SBPs have been grouped based on their substrate specificity, their sequence similarity or the topological arrangements of the $\beta$-sheets (Fukami-Kobayashi et al., 1999). In 2010, a new classification of SBPs was proposed based on the 3D alignments of the available protein structures. Six different classes known as clusters A to F were proposed (Berntsson et al., 2010). Very recently, a new cluster, G, was incorporated to make a total of 7 clusters (Scheepers et al., 2016) (Table 2). The main structural differences among these clusters are the presence of different interconnecting elements between the two domains that act as a hinge region (a long rigid $\alpha$-helix, one or several $\beta$ sheets with different length, etc.) and the presence of additional domains. Another structural difference is found concerning the binding of the substrate. While in most SBPs, ligand binding induces a substantial domain rotation resulting in closure of the two domains (the so called "venus fly-trap" mechanism (Mao et al., 1982)), in the case of ionic transporters no large movement is observed upon substrate binding. Below the available 3D structures of the SBP are reviewed according to the function of the associated $\mathrm{ABC}$ transporter.

\subsection{Iron and cation transporters}

As explained before, this group is the most represented in the PDB. Iron is an essential nutrient for all organisms, thus vertebrate hosts uses efficient iron sequesters (the so-called siderophores), like transferrin, to prevent bacterial invading pathogens proliferation by neglecting them access to available Fe(II) (Hammer and Skaar, 2011). In response, $S$. aureus, has evolved a sophisticated mechanism to respond to iron 
Table 1A

S. aureus USA300 Lpp.

\begin{tabular}{|c|c|c|c|c|c|}
\hline Locus Uniprot & Other locus & Name & Function $\left({ }^{b}\right)$ & $\mathrm{PDB}^{\mathrm{a}}$ & References \\
\hline & & & Fe Transport & & \\
\hline A0A0H2XGM1 (303 аa) & SAUSA300_1978 & FhuD1 & Ferric hydroxamate receptor & & $\begin{array}{l}\text { (Sebulsky and Heinrichs, 2001; Sebulsky } \\
\text { et al., 2004) }\end{array}$ \\
\hline A0A0H2XFG0 (303 аa) & SAUSA300_2235 & FhuD2 & Fe $\mathrm{ABC}$ transporter & 4FKM, 4FMNA, 4FIL, 4B8Y & $\begin{array}{l}\text { (Mariotti et al., 2013; Podkowa et al., } \\
\text { 2014; Sebulsky and Heinrichs, 2001; } \\
\text { Sebulsky et al., 2004) }\end{array}$ \\
\hline A0A0H2XKM7 (342 аa) & SAUSA300_0721 & $\begin{array}{l}\text { SstD, YclQ, } \\
\text { CeuE }\end{array}$ & Transferrin receptor & & \\
\hline А0АОН2ХНК0 (330) & SAUSA300_0117 & SirA & Fe $\mathrm{ABC}$ transporter & 3MWF, 3MWG & (Heinrichs et al., 1999) \\
\hline Q7A652 (292 aa) & SAUSA300_1032 & LsdE, SirF & $\mathrm{Fe} A B C$ transporter & 2Q8P, 2Q8Q & (Grigg et al., 2007) \\
\hline Q2FJS0 (284 aa) & SAUSA300_0344 & Efem, Efeo & $\begin{array}{l}\text { Efem/EfeO family lipoprotein } \\
\text { lipidation }\end{array}$ & & \\
\hline А0A0H2XEB0 (327 аa) & SAUSA300_2136 & HstA & $\mathrm{Fe} A B C$ transporter & 3EIX, 3EIW, 3LI2, 3LHS & (Beasley et al., 2009) \\
\hline A0A0H2XH19 (322 аa) & SAUSA300_0219 & & Iron Binding Protein & & \\
\hline A0A0H2XI48 (309 аa) & SAUSA300_0618 & MntC (SitC) & $\begin{array}{l}\text { Other cation transporters } \\
\text { Manganese-binding protein }\end{array}$ & $4 \mathrm{~K} 3 \mathrm{~V}$ & $\begin{array}{l}\text { (Gribenko et al., 2013; Gribenko et al., } \\
\text { 2016) }\end{array}$ \\
\hline A0A0H2XDI1 (516 aa) & SAUSA300_2351 & AdcAII-like & Zinc-binding & & \\
\hline A0A0H2XH66 (532 аa) & SAUSA300_2411 & Opp1A & $\begin{array}{l}\text { Cobalt and nickel transporter } \\
\text { Cnt }\end{array}$ & & (Remy et al., 2013) \\
\hline A0A0H2XGI8 (491 aa) & SAUSA300_0231 & NikA & Nickel ABC transporter & $\begin{array}{l}\text { 4XKR, 4XKQ, 4XKP, 4XKN, } \\
\text { 4OFJ, 3RQT }\end{array}$ & (Lebrette et al., 2015) \\
\hline A0A0H2XIF6 (591 aа) & SAUSA300_0203 & & $\begin{array}{l}\text { Nickel-Peptide/transporter } \\
\text { substrate-binding protein- }\end{array}$ & & \\
\hline A0A0H2XGY9 (260 aа) & SAUSA300_2230 & ModA & Molybdenum ABC transporter & & (Neubauer et al., 1999) \\
\hline $\begin{array}{l}\text { Q2FH48 (327 aa) } \\
\text { A0A0H2XKE4 (318 aa) } \\
\text { A0A0H2XJJ1 (324 aa) }\end{array}$ & $\begin{array}{l}\text { SAUSA300_1283 } \\
\text { SAUSA300_0145 } \\
\text { SAUSA300_0175 }\end{array}$ & PstS & $\begin{array}{l}\text { Anion Transporters } \\
\text { Phosphate } A B C \text { transporter } \\
\text { Phosphonate } A B C \text { transporter } \\
\text { Nitrate } A B C \text { transporter } \\
\text { substrate-binding protein }\end{array}$ & 3UN6 & \\
\hline A0A0H2XIQ0 (313 aа) & SAUSA300_2391 & OpuCc & $\begin{array}{l}\text { AA peptide transport } \\
\text { Glycine betaine/carnitine/ } \\
\text { choline } \mathrm{ABC} \text { transporter }\end{array}$ & 3066 & \\
\hline А0А0H2XK42 (259 аa) & SAUSA300_2359 & - & Amino acid $\mathrm{ABC}$ transporter & & \\
\hline A0A0H2XIR7 (517 aa) & SAUSA300_0073 & - & Peptide ABC transporter & & \\
\hline A0A0H2XIJ5 (551 aa) & SAUSA300_0891 & Opp3A & Oligopeptide $\mathrm{ABC}$ transporter & & \\
\hline A0A0H2XGK4 (571 aa) & SAUSA300_0892 & Opp4A & Oligopeptide $\mathrm{ABC}$ transporter & & \\
\hline A0A0H2XFT9 (280 aа) & SAUSA300_0437 & $\mathrm{GmpC}$ & NLPA/D-Methionine binding & 1 P99 & (Williams et al., 2004) \\
\hline A0A0H2XEA1 (273 aа) & SAUSA300_0798 & - & D-Methionine ABC transporter & & \\
\hline A0A0H2XEQ7 (423 aа) & SAUSA300_0209 & & $\begin{array}{l}\text { Sugar transport } \\
\text { Maltose } \mathrm{ABC} \text { transporter }\end{array}$ & 4HS7, 4HW8 & \\
\hline A0A0H2XG95 (399 аa) & SAUSA300_1884 & Cams & $\begin{array}{l}\text { Biosynthesis } \\
\text { CamS sex pheromone } \\
\text { biosynthesis }\end{array}$ & 2QX2 & \\
\hline $\begin{array}{l}\text { Q2FI17 (366 aa) } \\
\text { A0A0H2XH45 (146 aa) }\end{array}$ & $\begin{array}{l}\text { SAUSA300_0963 } \\
\text { SAUSA300_0693 }\end{array}$ & $\begin{array}{l}\text { QoxA } \\
\text { SaeP }\end{array}$ & $\begin{array}{l}\text { Respiration } \\
\text { Quinol oxidase, subunit II } \\
\text { Electron transfer domain }\end{array}$ & & \\
\hline & & & Chaperone/Foldase & & \\
\hline Q2FFQ5 (320 aa) & SAUSA300_1790 & PrsA & Foldase protein & $2 \mathrm{JZV}$ & (Heikkinen et al., 2009) \\
\hline Q9S446 (206 aa) & & SrtA & Sortase. & 1IJA, 1T2P, 1T2W & $\begin{array}{l}\text { (Ilangovan et al., 2001; Zong et al., } \\
\text { 2004) }\end{array}$ \\
\hline A0A0H2XFS3 (199 aа) & SAUSA300_2354 & DsbA & $\begin{array}{l}\text { Thioredoxin/Protein disulfide- } \\
\text { isomerase }\end{array}$ & 3BCI, 3BD2, 3ВCK & (Heras et al., 2008) \\
\hline Q2FF36 (290 aa) & SAUSA300_2046 & $\begin{array}{l}\text { YidC } \\
(\text { OxaA) }\end{array}$ & $\begin{array}{l}\text { Protein Translocation } \\
\text { YidC (OxaA)-essential protein }\end{array}$ & & \\
\hline A0A0H2XE22 (401 aa) & SAUSA300_1438 & PhiSLT & $\begin{array}{l}\text { Phage and Plasmid encoded Lpp } \\
\text { ORF144-like }\end{array}$ & & \\
\hline pUSA300_HOUMR0011 & $\begin{array}{l}\text { pUSA300_- } \\
\text { HOUMR0011 }\end{array}$ & BlaZ & Membrane bound penicillinase & $\begin{array}{l}\text { 3BLM, 1PIO, 1KGF, 1DJC, 1DJB, } \\
\text { 1DJA, 1KGE, 1OME, 1KGG, } \\
\text { 1GHP, 1GHM, 1GHI }\end{array}$ & $\begin{array}{l}\text { (Chen and Herzberg, 2001; Chen et al., } \\
\text { 1996) }\end{array}$ \\
\hline & & & \multicolumn{3}{|l|}{ Lpl cluster } \\
\hline Q2FJK4 (257 aа) & SAUSA300_0410 & & Lpl-1 $\nu$ Sa $\alpha$ specific & & (Nguyen et al., 2015a,b) \\
\hline Q2FJK3 (266 aа) & SAUSA300_0411 & & Lpl-2 $\nu$ Sa $\alpha$ specific & & (Nguyen et al., 2015a,b) \\
\hline Q2FJK2 (266 aа) & SAUSA300_0413 & & Lpl-3 $\nu$ Sa $\alpha$ specific & & (Nguyen et al., 2015a,b) \\
\hline Q2FJK1 (256 aа) & SAUSA300_0414 & & Lpl-4 $\nu$ Sa $\alpha$ specific & & (Nguyen et al., 2015a,b) \\
\hline Q2FJK0 (263 aа) & SAUSA300_0415 & Lpl3 & Lpl-5 $\nu$ Sa $\alpha$ specific & & (Nguyen et al., 2015a,b) \\
\hline Q2FJJ9 (258 aa) & SAUSA300_0416 & & Lpl-6 $\nu$ Sa $\alpha$ specific & & (Nguyen et al., 2015a,b) \\
\hline Q2FJJ8 (270 aa) & SAUSA300_0417 & & Lpl-7 $\nu$ Sa $\alpha$ specific & & (Nguyen et al., 2015a,b) \\
\hline
\end{tabular}


Table 1A (continued)

\begin{tabular}{|c|c|c|c|c|c|}
\hline Locus Uniprot & Other locus & Name & Function $\left({ }^{b}\right)$ & $\mathrm{PDB}^{\mathrm{a}}$ & References \\
\hline Q2FJJ7 (261 aa) & SAUSA300_0418 & & Lpl-8 $\nu$ Sa $\alpha$ specific & & (Nguyen et al., 2015a,b) \\
\hline Q2FJJ6 (270 aa) & SAUSA300_0419 & & Lpl-9 $\nu$ Saa specific & & (Nguyen et al., 2015a,b) \\
\hline Q2FE15 (261 aa) & SAUSA300_2429 & & Tandem lpp & & \\
\hline Q2FE14 (257 aa) & SAUSA300_2430 & & Tandem lpp & & \\
\hline Q2FKG1 (255 aa) & SAUSA300_0100 & Csa1A & $\begin{array}{l}\text { Conserved staphylococcal } \\
\text { antigen } 1 \mathrm{~A}\end{array}$ & 4BIH & (Nguyen et al., 2015a,b) \\
\hline Q2FKG0 (256 aa) & SAUSA300_0101 & Csa1B & $\begin{array}{l}\text { conserved staphylococcal } \\
\text { antigen } 1 \mathrm{~B}\end{array}$ & 4BIG & (Nguyen et al., 2015a,b) \\
\hline Q2FKF9 (255 aa) & SAUSA300_0102 & & Tandem lpp & & \\
\hline \multirow[t]{2}{*}{ Q2FKF8 (255 aa) } & SAUSA300_0103 & & Tandem lpp & & \\
\hline & & & Other/unknown & & \\
\hline A0A0H2XFS1 (181 aa) & SAUSA300_0079 & YdhK-like & Unknown & & \\
\hline A0A0H2XH82 (190 aа) & SAUSA300_0372 & PepSY & Unknown & & \\
\hline A0A0H2XHE2 (208 aa) & SAUSA300_0377 & & Unknown & & \\
\hline A0A0H2XGW7 (193 aa) & SAUSA300_1492 & & Unknown & & \\
\hline A0A0H2XIX8 (208 aа) & SAUSA300_0992 & & Unknown & 2AP3 & \\
\hline A0A0H2XG58 (151 aa) & SAUSA300_2403 & & Unknown & & \\
\hline A0A0H2XIF2 (292 aа) & SAUSA300_0724 & & Unknown & & \\
\hline Q2FEC8 (209 aa) & SAUSA300_2315 & & Unknown & & \\
\hline А0АОН2ХЕH9 (374 aа) & SAUSA300_2614 & & Unknown & & \\
\hline A0A0H2XGB5 (131 aa) & SAUSA300_0663 & & Unknown & & \\
\hline A0A0H2XF17 (317 aa) & SAUSA300_1106 & & Unknown & & \\
\hline A0A0H2XGB8 (124 aа) & SAUSA300_0303 & & Unknown & & \\
\hline А0А0Н2ХHН5 (118 аa) & SAUSA300_1478 & & Unknown & & \\
\hline A0A0H2XIE6 (304 aa) & SAUSA300_1376 & & Unknown & & \\
\hline A0A0H2XK53 (305 aа) & SAUSA300_1379 & & Unknown & & \\
\hline А0А0Н2ХET3 (289 аa) & SAUSA300_1440 & & Unknown & & \\
\hline A0A0H2XFX0 (156 aа) & SAUSA300_1742 & & Unknown & & \\
\hline A0A0H2XJH2 (51 aa) & SAUSA300_1741 & & Unknown & & \\
\hline A0A0H2XHH4 (242 aa) & SAUSA300_0769 & & Unknown & 3QFG & \\
\hline
\end{tabular}

a Protein data bank (PDB) (https://www.rcsb.org/pdb/home/home.do) access on 17/07/2017.

${ }^{\mathrm{b}}$ Depending on the protein, Lpp function has been experimentally or putatively assigned as indicated in the associated reference.

starvation that includes switching to fermentative metabolism, to decrease the local $\mathrm{pH}$, to force the release of iron from host transferrin or to increase the number of expressed iron Lpp scavengers (Friedman et al., 2006; Hammer and Skaar, 2011). Interestingly, the situation for $S$. pneumoniae is quite different. Iron uptake in $S$. pneumoniae bacterium depends entirely on the orphan response regulator RitR. However, although deletion of ritR affects pneumococci growth, this defect can be completely supressed by the addition of manganese (Ong et al., 2013). In contrast with $S$. aureus, $S$. pneumoniae does not dependent on iron but requires a highly efficient $\mathrm{Mn}^{2+}$ transporter, like PsaA. Moreover, $\mathrm{Mn}^{2+}$ plays a key role in the oxidative stress protection for this catalase negative pathogen that uses $\mathrm{H}_{2} \mathrm{O}_{2}$ as a chemical weapon against niche competitors and that colonizes the respiratory tract (Selva et al., 2009). Indeed, lack of PsaA makes the strain unable to deal with redox stress (Tseng et al., 2002).

The structures of four $S$. aureus SBP Lpp involved in iron uptake have been reported (FhuD2, SirA, HtsA, IsdE) (Fig. 3A, Table 1B). FhuD2 (Fe ABC transporter) and FhuD1 (Ferric hydroxamate receptor) are homologous SBPs (41\% sequence identity) that, interestingly, exhibit different activities. FhuD2 is conserved in other bacterial species and binds to a broad spectrum of Fe chelators. However, FhuD1 seems to be restricted to staphylococcal species and only binds ferrichrome and ferrioxamine B. Although FhuD1 structure remains unknown, the $\mathrm{X}$-ray structures of FhuD2 in complex with ferrichrome and ferrioxamine-B reveals the characteristic bilobate fold of cluster A, that accommodates the ligands between both lobes (PDB 4B8Y and PDB 4FIL), (Mariotti et al., 2013). SirA, the staphylo-ferrin B (SB) receptor, belongs to the same SBP cluster A. Its 3D structure (PDB 3MWF) presents the Nand C-terminal lobes bridged by a single $\alpha$-helix that, together with both lobes, defines the siderophore (FeSB in this case) binding site (Grigg et al., 2010a). SirA undergoes conformational change upon FeSB binding, affecting the conformation of two loops from the C-terminal domain to enclose FeSB. The staphylococcal HtsA is homologous to SirA (rmsd $2.11 \AA$ over $179 \mathrm{C} \alpha$ alignment) and its crystal structure represents the first for a Gram-positive siderophore-receptor complex (PDB 3EIW, PDB 3EIX and 3LI2) (Beasley et al., 2009). In a similar way to SirA, HtsA exhibits two different conformations depending on the presence or absence of bound ferric ligand into the binding site that is recognized through interaction with a six-arginine patch (Grigg et al., 2010b). However, in HtsA the siderophore-protein contacts are almost entirely different, and siderophore binding also induces distinct conformational changes affecting different loops. Thus, although both SirA and HtsA bind siderophores from the same $\alpha$-hydroxycarboxylate class, the structural features of each receptor provide an explanation for their distinct specificity (Grigg et al., 2010b). Finally, the staphylococcal IsdE (also named SirF) structure (PDB 2Q8P) was reported in complex with heme, in a hexa-coordinated fashion mode by Met78 and His229 (Grigg et al., 2007).

S. pneumoniae has two Lpp iron uptake SBP of known structure, PiaA and PiuA (Fig. 3A, Table 1B). Both SBPs share a similar folding containing the same structural elements found in SBPs from cluster A. In the PiaA structure (PDB 4HMQ), a molecule of ferrichrome is stabilized by several highly-conserved residues at the inter-domain cleft (Cheng et al., 2013). Upon ferrichrome binding, two highly flexible segments at the entrance of the cleft undergo significant conformational changes, indicating their contribution to the binding and/or release of ferrichrome. Furthermore, two conserved PiaA residues: Glu119 and Glu262 are proposed to form salt bridges with two arginines of the permease subunits (Fig. 3A). As expected, similar motifs are found for the PiuA SBP (PDB 4JCC). 
Table 1B

S. pneumoniae TIGR4 Lpp.

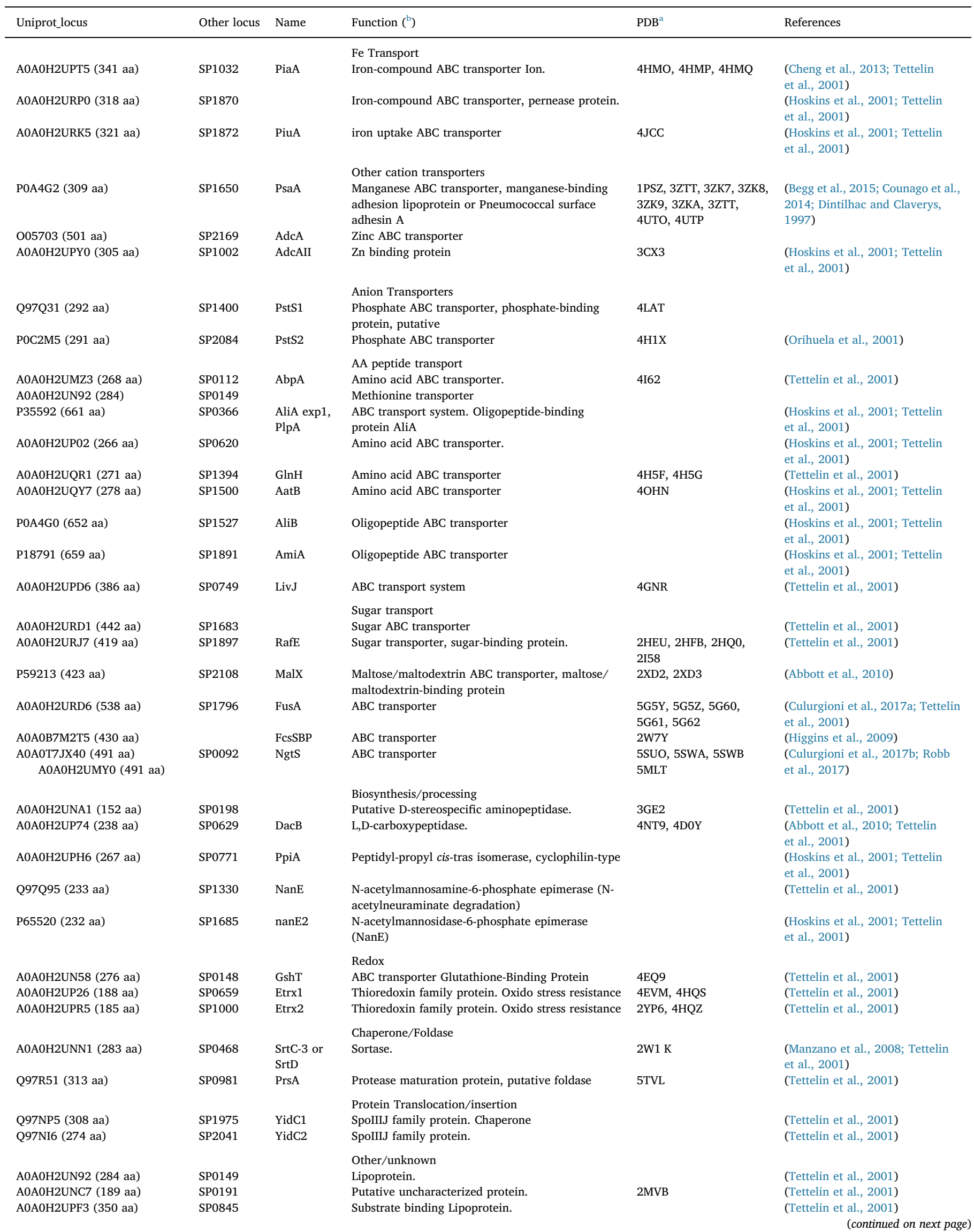


Table 1B (continued)

\begin{tabular}{|c|c|c|c|c|c|}
\hline Uniprot_locus & Other locus & Name & Function $\left({ }^{b}\right)$ & $\mathrm{PDB}^{\mathrm{a}}$ & References \\
\hline A0A0H2UPN3 (307 aa) & SP0859 & & DUF979 superfamily. Unknown function & & (Tettelin et al., 2001) \\
\hline A0A0H2URB7 (445 aa) & SP1690 & & $\mathrm{ABC}$ transporter & & (Tettelin et al., 2001) \\
\hline A0A0H2URL4 (355 aа) & SP1826 & & $\mathrm{ABC}$ transporter & & (Tettelin et al., 2001) \\
\hline A0A0H2URR9 (167 aa) & SP1916 & & PAP2 family protein & & \\
\hline A0A0H2URP6 (206 aa) & SP1945 & & Hypothetical Protein & & \\
\hline A0A0H2US66 (335 аa) & SP2197 & & $\mathrm{ABC}$ transporter & & (Tettelin et al., 2001) \\
\hline
\end{tabular}

${ }^{\text {a }}$ Protein data bank (PDB) (https://www.rcsb.org/pdb/home/home.do) access on 17/07/2017.

${ }^{\mathrm{b}}$ Depending on the protein, Lpp function has been experimentally or putatively assigned as indicated in the associated reference.

\subsection{Other cation transporters}

Pneumococcal $\mathrm{Zn}^{2+}$ AdcAII receptor and, in particular, the $\mathrm{Mn}^{2+}$ PsaA receptor are critical for a non-strong iron dependent pathogen survival (Tseng et al., 2002). Indeed, these proteins are widespread and named laminin-binding proteins in other bacterial species. The threedimensional structures of AdcAII (PDB 3CX3 (Loisel et al., 2008)) and PsaA (PDB 3ZTT) (Lawrence et al., 1998) have been reported (Fig. 3B, Table 1B). Both proteins present a similar fold typical from cluster A, the main difference being the conformation of a flexible loop that is located at the entrance of the binding site. In both structures a $\mathrm{Zn}^{2+}$ cation is found in the interdomain cleft, stabilized by a tetrahedral coordination through three His and one Glu residues. Despite the first reported crystal structure of PsaA contains $\mathrm{Zn}^{2+}$, in vivo and in vitro data indicated that $\mathrm{Mn}^{2+}$ is the natural substrate for this transport system (Dintilhac and Claverys, 1997). The structure of metal-free PsaA reveals an open conformation with the metal-binding site completely exposed to the solvent (PDB 3ZK7, PDB 3ZK8, PDB 3ZK9 (Counago et al., 2014)). The structure of PsaA in complex with $\mathrm{Mn}^{2+}$ is also available (PDBID 3ZKA, (Counago et al., 2014)). The inability of openstate PsaA to satisfy the preferred coordination chemistry of $\mathrm{Mn}^{2+}$ enables the protein to undergo the conformational changes required for cargo release to the Psa permease. Despite this difference in metal ion affinities, high-resolution structures of PsaA in complex with $\mathrm{Mn}^{2+}$
(PDBID 3ZTT (McDevitt et al., 2011)) (Fig. 3B) or $\mathrm{Zn}^{2+}$ showed almost no difference. In addition, the structure of PsaA in complex with $\mathrm{Cd}^{2+}$ has also been reported (PDB 4UTP, PDB 4UTO (Begg et al., 2015)).

$S$. aureus presents other Lpps that are involved in cation transport. Besides iron transporters there are cation transporters for $\mathrm{Co}, \mathrm{Cu}, \mathrm{Mn}$, $\mathrm{Mo}, \mathrm{Ni}, \mathrm{Zn}$ ions, which become important when these trace elements are limited. In some cases, they are crucial in infection. Such is the case of MntC, (also named SitC) one of the most abundant Lpp in S. aureus. MntC is the metal-binding protein component of the $\mathrm{Mn}^{2+}$-specific mntABC transporter and belongs to the SBP cluster A. The protein is expressed during the early stages of infection and is currently being tested in human clinical trials as a component of a multi antigen vaccine for the prevention of $S$. aureus infections (Gribenko et al., 2013). The crystal structure suggests two potential metal binding modes, which may lead to reversible as well as irreversible metal binding (PDBID 4K3 V (Gribenko et al., 2013)). The X-ray structure of MntC was also solved in complex with two different antibody fragments that were selected because they prevent the capture and transport of $\mathrm{Mn}^{2+}$, a key element that the pathogen uses to evade host immunity (Fig. 3B) (Gribenko et al., 2016).

Nickel is a transition metal required as a cofactor for several bacterial enzymes. $S$. aureus possesses two canonical $\mathrm{ABC}$-importers dedicated to nickel acquisition: the NikABCDE and the CntABCDF systems. The structure of the extracytoplasmic nickel-binding component NikA

Table 2

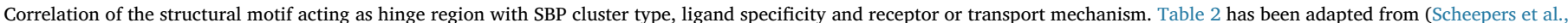
2016). Very recently, at least five new SBPs with different structural arrangement have been assigned to a new cluster, cluster G.

\begin{tabular}{|c|c|c|c|}
\hline Cluster & Structural motif acting as hinge region & Substrate & Associated with \\
\hline A-I & Single $\alpha$-helix & Metal ions & Type II ABC transporter \\
\hline A-II & & $\begin{array}{l}\text { Siderophores, hemes, vitamin } \mathrm{B} 12 \text {, } \\
\text { molybdate, tungstate }\end{array}$ & \\
\hline B-I & Three interconnecting strands & Sugars, sugar alcohols, autoinducer 2 & $\begin{array}{l}\text { Type I ABC transporter, } 2 \text { component sensor } \\
\text { kinase, transcription factor }\end{array}$ \\
\hline B-II & Second interconnecting strand interrupted by one $\alpha$-helix & Amino acids & Type I ABC transporter \\
\hline B-III & Second interconnecting strand interrupted by two $\alpha$-helixes & Aromatic acids & \\
\hline B-IV & $\begin{array}{l}\text { One } \alpha \text {-helix interrupting the strand hinge. In addition, this cluster } \\
\text { shows a glycan moiety }\end{array}$ & Natriuretic Compounds & Natriuretic peptide receptor \\
\hline $\mathrm{B}-\mathrm{V}$ & Two small $\alpha$-helixes interrupting the strand hinge & Glutamate & G-protein-coupled receptor \\
\hline $\mathrm{C}$ & An additional domain is present in between the two lobes & $\begin{array}{l}\text { Di- and Oligopeptides, cellobiose, opine, } \\
\text { nickel }\end{array}$ & Type I ABC transporter \\
\hline D-I & The hinge-region consists of two short strands, $4-5$ amino acids & Sugars, sugar alcohols, spermidine/putrescine & Type I ABC transporter \\
\hline D-I & long & Thiamine, spermidine/putrescine & Type I ABC transporter, transcription factor \\
\hline D-IIIa & & Phosphate, molybdate, tungstate & Type I ABC transporter \\
\hline D-IIIb & & Molybdate, tungstate & \\
\hline D-IV & & Iron ions & \\
\hline E-I & One large $\alpha$-helix & $\begin{array}{l}\text { Organic acids, amino alcohols, dipeptides, } \\
\text { glycerol-3-phosphate }\end{array}$ & TRAP transporter \\
\hline E-II & & Amino acids & TT transporter \\
\hline F-I & $\begin{array}{l}\text { Two strand hinges that almost double the length compared with } \\
\text { cluster D }\end{array}$ & $\begin{array}{l}\text { Thiamine, pyrimidines, sulfonates, } \\
\text { bicarbonate }\end{array}$ & Type I ABC transporter \\
\hline F-II & & Methionine & \\
\hline F-III & & Compatible solutes & \\
\hline F-IV & & Amino acids & $\begin{array}{l}\text { Type I ABC transporter, ligand-gated ion channel, } \\
\text { G-protein-coupled receptor }\end{array}$ \\
\hline G & $\begin{array}{l}\text { The hinge region is formed by three loops. In addition, there is a } \\
\text { regulatory EF-hand-like calcium-binding site }\end{array}$ & Oligosaccharides & Type I ABC transporter \\
\hline
\end{tabular}


A Iron $A B C$ transporters (SBP Cluster A)
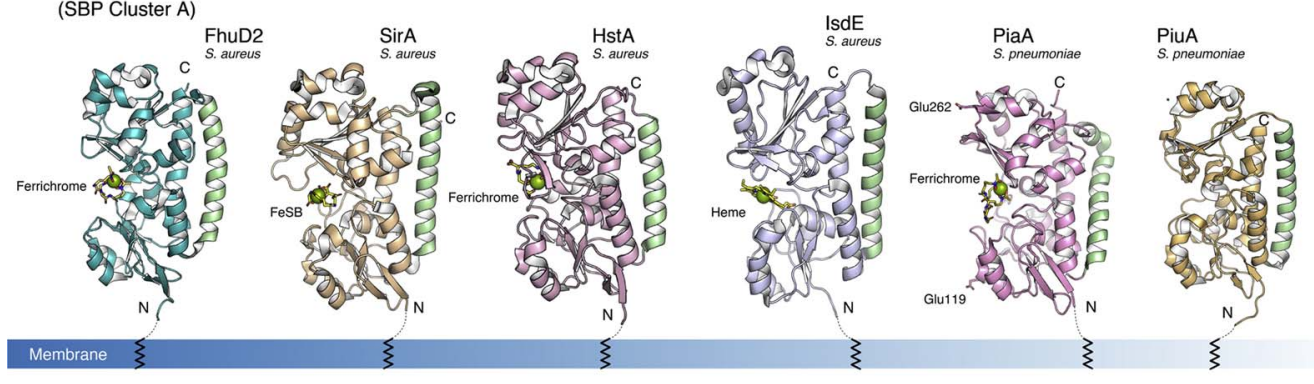

B Other cation $A B C$ transporters (SBP Cluster A)

\section{$\begin{array}{ll}\text { Other cation } A B C \text { transporters } & \text { Anion } A B C \text { transporters } \\ \text { (SBP Cluster } \mathrm{C} \text { ) } & \text { (SBP CLuster D) }\end{array}$}

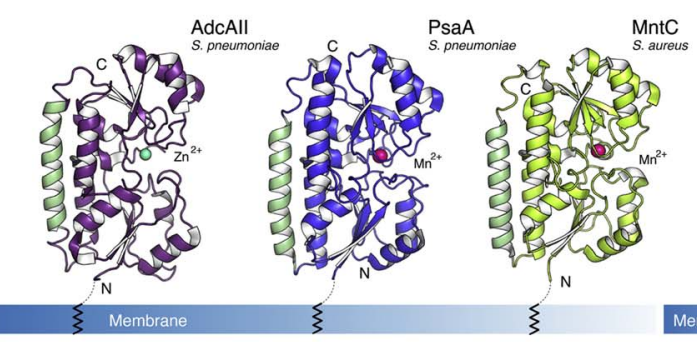

(SBP Cluster C)

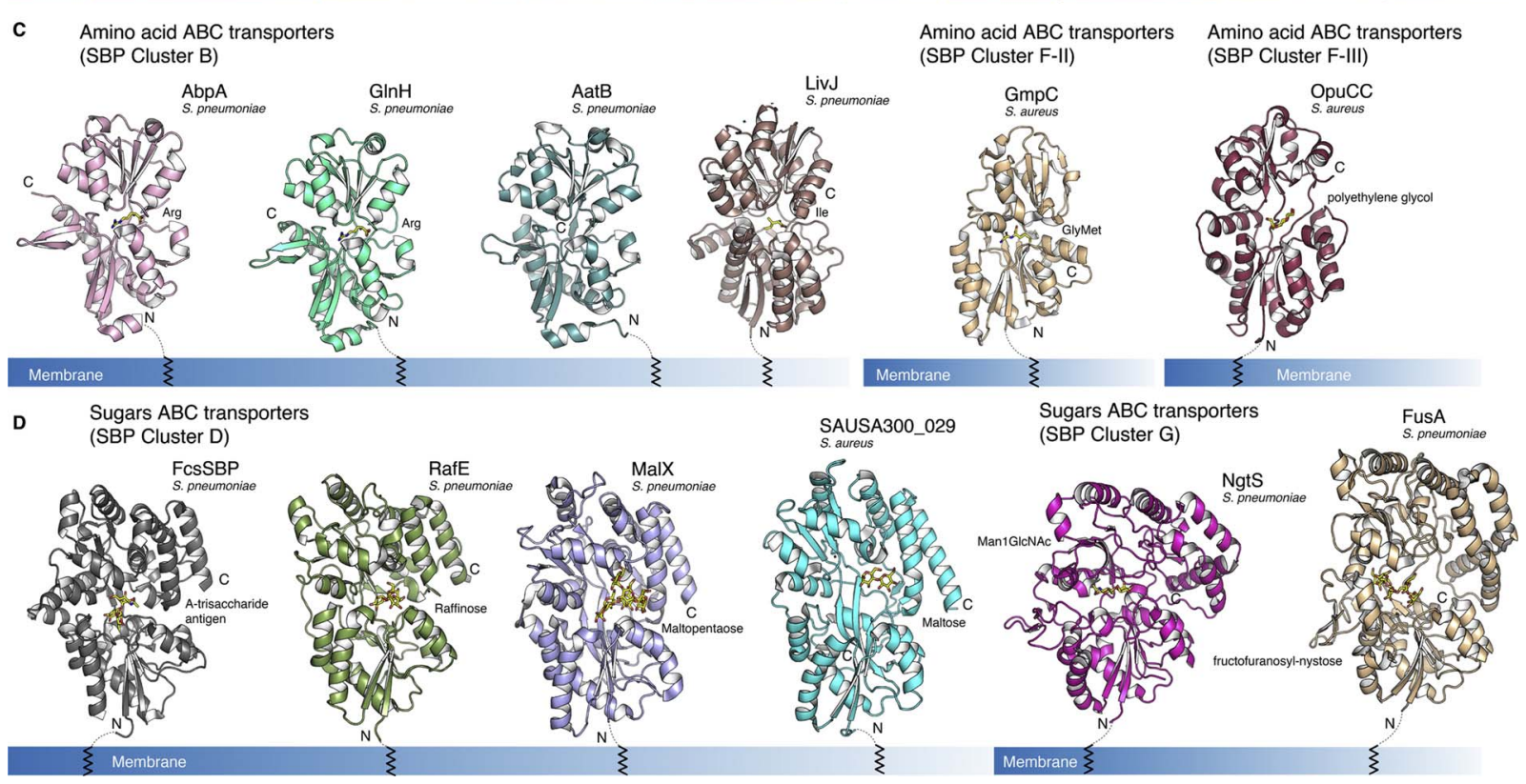

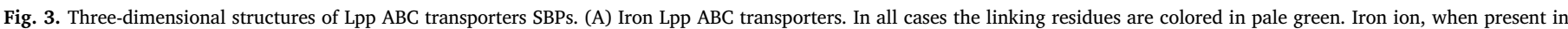

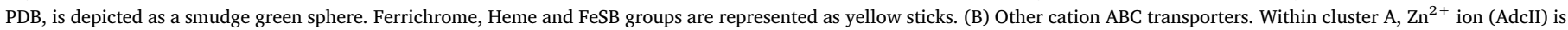

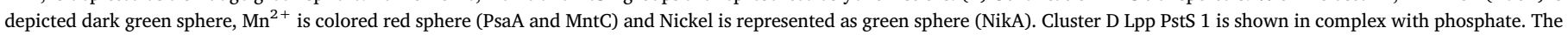

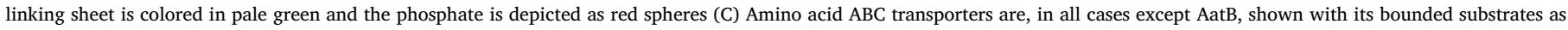

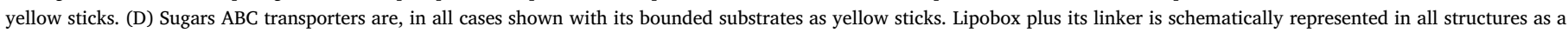

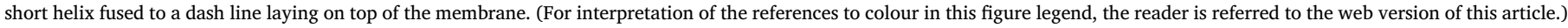

shows that is able to bind either a Ni-(L-His) $)_{2}$ (PDB 4XKQ, PDB 4XKP, PDB 4OFJ, PDB 3RQT and PDB 4XKN) complex or a Ni-(L-His) (2-methyl-thiazolidine dicarboxylate) (PDB 4XKR) complex (Fig. 3A). The protein binds specifically nickel complexes, in an opportunistic manner: if histidine is present in the bacteria's environment, the protein binds preferably $\mathrm{Ni}$-(L-His) $)_{2}$. Otherwise, it binds nickel chelated by available products of the metabolism (Lebrette et al., 2015). In addition to NikA, Cnt (previously annotated as Opp1A) is a novel identified cobalt and nickel transporter (Remy et al., 2013) (Table 1A).

\subsection{Anion and amino acid transporters}

Despite the suggested critical impact over bacterial virulence of ABC amino acid transporters, such as the pneumococcal putative methionine
Lpp Sp0149 transporter (Basavanna et al., 2009) or the PstS phosphate transporters (Zheng et al., 2016), few structural information is currently available for this kind of Lpp (Table 1). Two phosphate transporters in $S$. pneumoniae (PstS1, PstS2) have been structurally characterized (Table 1, Fig. 3B). PstS1 and Psts2 structures (PDBs 4LAT and 4H1X respectively) are included as members of the cluster $D$ that contains a $\beta$ hinge connecting the two lobes of the protein. The phosphate moiety is accommodated between the two lobes. No biochemical or functional data is yet available. Based on genetic annotation, the staphylococcal Lpp USA300_0175 is involved in nitrate transport. Its structure is available (PDB 3UN6), which has allowed its classification into subcluster F-I, which contains a $\beta$-hinge similar like cluster D but with almost double the length creating more flexibility inside the SBP.

The pneumococcal Lpp SBP amino acid components, ApbA, GlnH 
and AatB (PDBs 4I62, 4H5F and 4OHN respectively) present the two lobes connected by two longer strands, 8-10 amino acids long, a characteristic from cluster F (Berntsson et al., 2010; Scheepers et al., 2016). In these structures, the binding site is located between the two lobes just below of the connecting strands (Fig. 3C). Other example of predicted amino acid transporter is the pneumococcal LivJ (PDB 4GNR), which belong to cluster B. The three-dimensional structure reported for this protein is characterized by the presence of three interconnecting strands between the two domains and the presence of one $\alpha$ helix that interrupts the second interconnecting strand (Fig. 3B). However, no biochemical characterization is yet available to define its substrate specificity.

$S$. aureus has two amino acid $\mathrm{ABC}$ transporters of reported structure, GmpC (PDB 1P99) and OpuCc (PDB 3066) belonging to clusters F-II and F-III respectively (Fig. 3C, Table 1A). According to this classification, GmpC should bind D-methionine, however GmpC binds glycylmethionine dipeptide instead. A comparative analysis of the substrate-binding pocket within the family members reflects the modifications in the hydrophobic nature of $\mathrm{GmpC}$ active site allowing accommodation of the larger methionine-containing dipeptide (Williams et al., 2004). No associated study exists for OpuCc (PDB 3066).

\subsection{Sugar transporters}

The $\alpha$-glucans are believed to be just a carbon source for "freeliving" bacteria with little or no use in commensalism or pathogeny (Henrissat et al., 2002). However, the use of $\alpha$-glucan in soft tissue infections by bacterial pathogens has been reported (Graham et al., 2006). Interestingly, $S$. pneumoniae and $S$. aureus possess Lpp specialized in using $\alpha$-glucans in virulence (MalX in $S$. pneumoniae and protein encoded by gene SAUSA300_0209 in S. aureus). Furthermore, MalX has been shown to be critical for $S$. pneumoniae cells grow using exogenous host glycogen (Abbott et al., 2010). Indeed, Glycogen is a precursor in the synthesis of the surfactant by the alveolar type II cells and this might be correlated with the preference of $S$. pneumoniae to colonize this kind of cells (Cundell and Tuomanen, 1994).

Pneumococcal FcsSBP, RafE and MalX belong to the cluster D. The discernible feature of these proteins is their 4-5 amino-acids long hingeregion consisting of two short strands (Fig. 3D). FcsSBP was crystallized in complex with a A-trisaccharide (PDB 2W7Y) (Higgins et al., 2009) and MalX with maltopentaose (PDB 2XD3) (Abbott et al., 2010). Structural analysis and isothermal titration calorimetry (ITC) experiments revealed that FcsSBP binding is limited to trisaccharides, specifically to the soluble group A/B trisaccharides (Higgins et al., 2009). MalX bind glucooligosaccharides of different lengths with different affinities. A comparison of maltopentaose-MalX (PDB 2XD3) (Table 1B, Fig. 3D) with the apo-MalX (PDB 2XD2) demonstrated that recognition of longer maltooligosaccharides requires structural plasticity in this protein (Abbott et al., 2010). The only $S$. aureus maltose transporter available in the PDB (SAUSA300_029) (PDB 4HW8) is classified as D cluster member presenting the characteristic two lobes linked by a hinge-region. However, this structure has not been yet associated with any publication.

The Pneumococcal sugars transporters NgtS and FusA belong to the cluster G, presenting relative larger molecular weight, additional structural elements and a metal-binding site, which is located close to the SBP-membrane domain interface (Scheepers et al., 2016).

NgtS was co-crystallized with the Man1GlcNAc (PDB 5SWA) and Man5GlcNAc (PDB 5SWB); both complexes are in a "closed" conformation relative to the "open" conformation obtained in the absence of ligand (PDB 5SUO). As with other SBPs, the ligand-binding site was found at the interface of the two domains and ligand recognition involves a transition from the open, unbound form to a ligand-stabilized closed form (Robb et al., 2017). In parallel, Curlurgioni and co-workers reported the monomeric and oligomeric species to NgtS. The tridimensional structure revealed that the residues 361-491 are positioned in different conformation (Culurgioni et al., 2017a) compared with the structure without ligand reported by Robb and co-workers (Robb et al., 2017). This region is interacting with other symmetryrelated monomer producing a domain-swapped dimer, that could be used as an oligomerization mechanism to regulate carbohydrate binding (Culurgioni et al., 2017a). The FusA (Fig. 3B) presents high affinity for longer fructooligosaccharides (tetrasaccharides and larger). The structural superposition of the complexes of FusA with kestose (PDB 5G5Z), nystose (PDB 5G60), and fructofuranosyl-nystose (PDB 5G61) showed a similar overall conformation compared with apo-FusA (PDB 5G5Y), thus, indicating the absence of conformational changes triggered by ligand. The structural analysis of the three FusA complexes revealed the conserved binding site (Culurgioni et al., 2017b).

\section{Three-dimensional structures of Lpp involved in redox processes and respiration}

One of the most interesting aspects of the pneumococcal biology is its ability to survive under highly oxidizing conditions. Thus, on top of other mechanisms, pneumococci have evolved to have specific Lpp to deal with ROS stress. This bacterium, lacking catalase (the enzyme catalysing the decomposition of hydrogen peroxide to water and oxygen), presents in its lipoproteome two thiorredoxin-like Lpp, Etrx1 and Etrx2, both critical for virulence (Saleh et al., 2013), and the Glutathione scavenger GshT. In contrast, $S$. aureus has a Quinol oxidase (QoxA), an electron transporter component (SaeP) and a thiorredoxin Lpp (DsbA). However, none of them seems to be related with redox resistance but instead with respiration and protein folding mechanisms (Table 1A and 1B, Fig. 4A).

No structural or functional characterization of $S$. aureus Lpp respiration proteins QoXA and SaeP was available at the date of query. Luckily, all pneumococcal Lpp redox proteins have been structurally and functionally characterized (Saleh et al., 2013). Pneumococcus tolerates high concentrations of ROS during the infection process, and even produces by itself large quantities of $\mathrm{H}_{2} \mathrm{O}_{2}$. This specific pneumococcal feature has a beneficial impact in niche competition. It has been reported that pneumococci use ROS particles to kill bacterial competitors as $S$. aureus (Selva et al., 2009). Furthermore, $\mathrm{H}_{2} \mathrm{O}_{2}$ plays a critical role in the infectious process allowing pneumococcal cells to invade lungs (Duane et al., 1993) and brain tissues (Braun et al., 2002). To deal with the challenge of surviving its own $\mathrm{H}_{2} \mathrm{O}_{2}$, pneumococci has developed an extremely robust ROS defence mechanism that requires the combined action of cytoplasmic, membrane embedded proteins, secreted proteins and Lpp (Ezraty et al., 2017; Yesilkaya et al., 2013). There are three Lpp involved in such a defense mechanism, two thiorredoxin-like lipoproteins (Etrx1, Etrx2), that are essential for external oxidative protein damage repair (Saleh et al., 2013), and a Gluthationebinding protein $\mathrm{ABC}$ transporter $\mathrm{GshT}$ that might contribute to provide protection against redox stress (Potter et al., 2012). The structures of Etrx1 and Etrx2 present a $\alpha / \beta$ thiorredoxin-like fold (Fig. 4A). Etrx2 is highly similar to Etrx1 but embellished by a central $\alpha \beta$ insertion and an $\mathrm{N}$-terminal $\beta$-hairpin. In both structures, the loop connecting $\beta 3$ with $\alpha 2$ contains the catalytic $\mathrm{CxxC}$ motif. Although structurally similar, the active site of Etrx 1 exhibit a more polar character while Etrx 2 is mainly hydrophobic that could account for specific recognition of the A and $B$ catalytic domains of the Methionine sulfoxide reductase MsrA/MsrB 2 (MsrAB2) during repairing of the damaged proteins (Saleh et al., 2013). Considering that Etrx2 was crystalized in complex with either Cyclofos$3^{\mathrm{rm}}$ detergent or with 2-Hydroxyethyl Disulfide (HED) ligands, both bound to the active site. This result opens the gate in the search for Etrx inhibitors (Fig. 4A).

The crystal structure of GshT has been solved (PDB code 4EQ9) but not associated publication is already available. GshT is an $\alpha / \beta$ protein containing two globular domains fused by a flexible linker. Interestingly, the interface between both domains defines the active 
A Redox \& Respiration

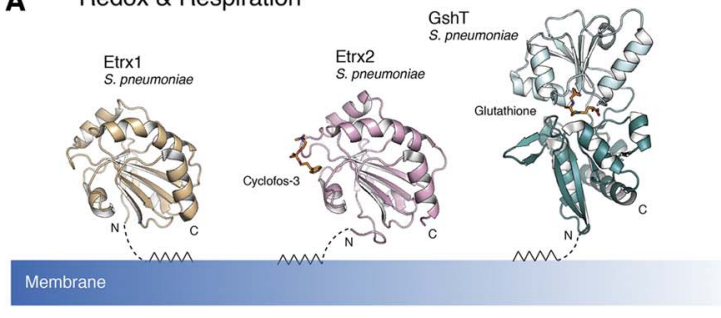

C Chaperone/Foldase

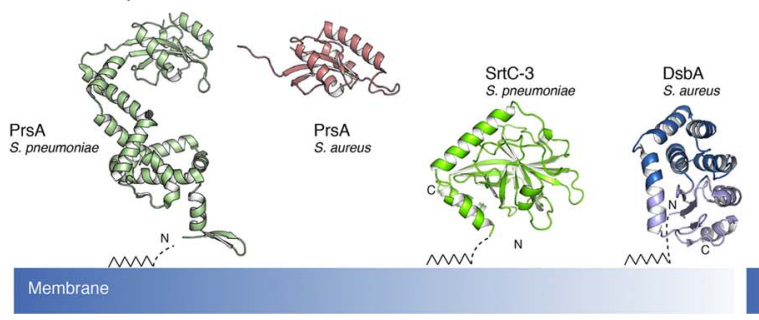

B

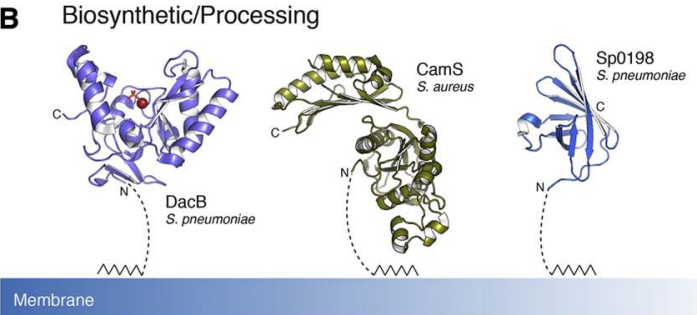

D

Other/Lpl cluster

Plasmid encoded Lpp

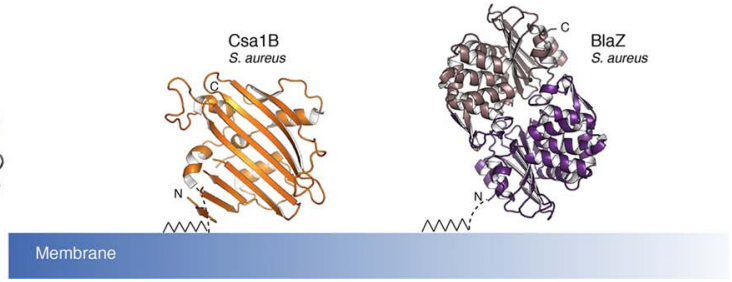

Fig. 4. Three-dimensional structures of the rest of Lpp categories. (A) Three-dimensional structures of Lpp involved redox/respiration. Etrx1 is displayed in its apo form, Etrx2 and GshT are displayed in complex with cyclofos-3 and Gluthathione, respectively. Both ligands are represented as red sticks. Domains composing GshT is colored differently. (B, C and D) miscellaneous families. (B) Biosynthetic/Processing Lpp. DacB Zinc ion is depicted as red sphere and phosphate is depicted in sticks. (C) Chaperone/Foldases. The partial structure of $S$. aureus PrsA (red) is shown close to the full length pneumococcal one for comparison (green). DsbA includes a thioredoxin domain which is colored in light blue and a helical insertion in dark blue. (D) Other/Lpp/Plasmid encoded Lpp groups. BlaZ is represented with two colors to reflect the bilobular architecture. (For interpretation of the references to colour in this figure legend, the reader is referred to the web version of this article.)

site, which in the reported GshT structure is complexed with Glutathione (Fig. 4A). However, no description of its functional properties is, hitherto, available.

\section{Three-dimensional structures of Lpp involved in biosynthesis and processing}

Bacterial lipoproteins are also involved in biosynthetic and processing pathways. Inside this group, the only reported structure from $S$. aureus is the so-called sex pheromone CamS (PDB code: 2QX2) (Fig. 4B), This Lpp is literally responsible for the transmission of plasmids between $S$. aureus strains being a critical virulence factor responsible for the acquisition of antibiotic resistance (Flannagan and Clewell, 2002). Its structure presents a novel folding composed by two domains: the $\mathrm{N}$ - and $\mathrm{C}$-terminal domains. $\mathrm{N}$-terminal domain has a core of four $\beta$-sheets surrounded by two long $\alpha$-helices, whereas C-terminal domain is composed by six $\beta$-sheets and two long $\alpha$-helices. In $S$. pneumoniae biosynthetic Lpp are related with nutrient processing and turnover of the peptidoglycan having a considerable impact on the microorganism virulence. This is the case of the pneumococcal 1,dcarboxypeptidase DacB that, besides its role in maintaining cell shape, is also relevant in cell adhesion and in susceptibility against vancomycin (Abdullah et al., 2014). The crystal structure of DacB (PDB code: 4D0Y) (Fig. 4B), presents a mononuclear $\mathrm{Zn}^{2+}$ catalytic center located in the middle of a large and fully exposed groove (Abdullah et al., 2014). Two different conformations were found presenting a different arrangement of the active site topology. The critical residues for catalysis and substrate specificity were identified. Comparison with DacA (the pneumococcal D,D-carboxypeptidase) revealed different regulatory mechanism: while DacA presents a fully open active site and a rigid structure, DacB lipoprotein presents a long flexible loop connecting the membrane with different regions of the cell-wall and two different conformations for the active site (Abdullah et al., 2014). Other example of $S$. pneumoniae biosynthetic Lpp is SP0198 (PDB code: 3GE2) (Fig. 4B). Although this protein has not been functionally characterized, its crystal structure revealed a beta barrel motif pointed by CATH database as a putative $\mathrm{D}$-stereospecific aminopeptidase. This protein holds the DUF3642 domain, a major virulence factor from gram-negative bacteria (Punta et al., 2012), suggesting that this lipoprotein could be involved in host-pathogen interactions in S. pneumoniae.

\section{Three-dimensional structures of Lpp involved in protein folding}

PrsA foldases are essential proteins ubiquitous within Gram-positive bacteria (Vitikainen et al., 2004) performing the cis-trans isomerization of the proline preceding peptide bonds acting as a folding chaperone (Fanghanel and Fischer, 2004). In this sense, staphylococcal PrsA has been reported as an essential factor for secreted proteins in $S$. aureus (Heikkinen et al., 2009) acting also as an auxiliary factor of oxacillin resistance in S. aureus (Jousselin et al., 2015). The Staphylococcal reported PrsA structure, comprising a shorter 110 residues construct (PDB $2 \mathrm{JZV}$ ), overlaps perfectly with the longest S. pneumoniae structure (274 residues) (PDB 5TVL). Pneumococcal PrsA structure contains a parvulin-type peptidyl-prolyl cis-trans isomerase domain (Fig. 4C).

Sortases are catalyse the covalent anchor of proteins to the peptidoglycan by cleaving between the threonine and glycine residues of the conserved LPXTG motif (where X represents any amino acid) in substrate proteins (Fischetti et al., 1990; Schneewind et al., 1992). There are two Lpp sortases structurally determined, one from $S$. aureus (SrtA, PDB 1IJA, 1T2P) and one from $S$. pneumoniae (SrtC-3, PDB 2W1 K) (Table $1 \mathrm{~A}$ and $1 \mathrm{~B}$ ). Both structures are formed by a $\beta$-barrel structure composed of eight anti-parallel $\beta$-strands linked by multiple $\alpha$ - and $3_{10}$ helices (Ilangovan et al., 2001; Manzano et al., 2008; Zong et al., 2004). The main difference between them is the additional $\alpha$-helix present at the SrtC-3C terminus and the presence of a "lid" over the active site region.

Other example of Lpp structurally reported within this category is the disulphide isomerase protein DsbA (PDB 3BCI) from $S$. aureus, which is involved in catalysing the disulphide bonds of the secreted proteins (Table 1A). Its crystal structure comprises a thioredoxin domain and an embedded helical domain (Heras et al., 2008) (Fig. 4C)

\section{Three-dimensional structures of miscellaneous Lpp}

A huge portion of the S. aureus lipoproteome (22\%) is classified as the specific $S$. aureus Lpl cluster whose only properly characterized members are the Cs1A (PDB 4BIH) and Cs1 B (PDB 4BIG), (Fig. 4D) antigens. These two proteins, with low structural similarity to any other 
known protein, have been suggested to be protective antigens with a clear role in pathogeny (Schluepen et al., 2013). As expected due to their high sequence identity (75\%), the overall fold of Csa1A is almost identical with that of Csa1 B (rms of $0.718 \AA$ over $144 \mathrm{c} \alpha$ aligned). Both structures exhibit a single $\alpha / \beta$ domain arranged as a large ten-stranded antiparallel $\beta$-sheet that closely resembles a $\beta$-half-barrel fold (Schluepen et al., 2013).

Within this miscellaneous category the only crystal structure reported is that of BlaZ from $S$. aureus (PDB 1PIO) (Fig. 4D). BlaZ is a $\beta$ lactamase composed by two close-packed domains where the polypeptide chain crosses twice from one domain to the other. One domain is formed by a five-stranded antiparallel beta-sheet with three helices packing against a face of the sheet. The second domain is formed mostly by helices that pack against the second face of the sheet. The active site is located in the interface between the two domains (Herzberg and Moult, 1987).

\section{Three-dimensional structures of Lpp withunknown function}

It is worth to mention that $28 \%$ of the $S$. aureus and $21.4 \%$ of the pneumococcal lipoproteome is largely unknown. Although some efforts have been done to structurally characterise this group of proteins, only one structures from $S$. pneumoniae (PDB code 2MVB) and two structures from S. aureus (PDB codes: 2AP3 and 3QFG) have been deposited in the but no available functional characterization is reported so far. Their structural features are awaiting classification.

\section{Concluding remarks}

Although, the average fraction of the lipoproteome in the context of the full bacterial genome is very low, just $1.7 \%$ of the $S$. pneumoniae TIGR4 genome and no more than $2.57 \%$ for the MRSA S. aureus strain USA300 (Madan Babu and Sankaran, 2002; Shahmirzadi et al., 2016), the impact of this limited set of exposed proteins in the adaptability and pathogenic capabilities of these two Gram-positive pathogens is huge. This review summarizes and brings together the functional and structural knowledge concerning this group of peripheral membrane proteins.

Despite fragmentary information we dispose for many of these Lpp, the few cases in which a more in depth, functional and structural, knowledge is available reveals that Lpp are essential in regulation of quite diverse processes. This regulation depends on specific protein-ligand and protein-protein interactions. Understanding of the molecular basis of these interactions, and thus, of the regulatory processes mediated by Lpp, is essential. In an era of multidrug resistance emergence, the critical impact of the small Lpp group in bacterial survival makes them extremely attractive candidates as novel vaccine antigens and antibiotic targets to control infections caused by bacterial pathogens. In this sense, more structural and functional studies in the Lpp family are required.

Another important challenge for the near future is structural characterization of the full-length lipoprotein in which both the lipid and protein components can be visualized. What could be the effect for the complete structure of Lpp when attached to the membrane? As previously mentioned, different kind of lipids have been found in Lpp, besides, most lipoproteins present a linker of variable length connecting their functional modules to the membrane; therefore, it is expected that, at least, for those Lpp having a short linker and/or functional domains lying close to the membrane, the full-length structure in the presence of membrane-mimicking molecules (detergents, amphipols, lipids, nanodiscs) would provide unexpected and important details key to understand in vivo functioning of Lpp.

\section{Acknowledgements}

This work has been supported by a grant from the Spanish Ministry of Economy and Competitiveness (BFU2014-59389-P) to JAH.

\section{References}

Abbott, D.W., Higgins, M.A., Hyrnuik, S., Pluvinage, B., Lammerts van Bueren, A., Boraston, A.B., 2010. The molecular basis of glycogen breakdown and transport in Streptococcus pneumoniae. Mol. Microbiol. 77, 183-199.

Abdullah, M.R., Gutierrez-Fernandez, J., Pribyl, T., Gisch, N., Saleh, M., Rohde, M., Petruschka, L., Burchhardt, G., Schwudke, D., Hermoso, J.A., Hammerschmidt, S., 2014. Structure of the pneumococcal 1,d-carboxypeptidase DacB and pathophysiological effects of disabled cell wall hydrolases DacA and DacB. Mol. Microbiol. 93, 1183-1206.

Alloing, G., de Philip, P., Claverys, J.P., 1994. Three highly homologous membranebound lipoproteins participate in oligopeptide transport by the Ami system of the gram-positive Streptococcus pneumoniae. J. Mol. Biol. 241, 44-58.

Babu, M.M., Priya, M.L., Selvan, A.T., Madera, M., Gough, J., Aravind, L., Sankaran, K., 2006. A database of bacterial lipoproteins (DOLOP) with functional assignments to predicted lipoproteins. J. Bacteriol. 188, 2761-2773.

Basavanna, S., Khandavilli, S., Yuste, J., Cohen, J.M., Hosie, A.H., Webb, A.J., Thomas, G.H., Brown, J.S., 2009. Screening of Streptococcus pneumoniae ABC transporter mutants demonstrates that LivJHMGF, a branched-chain amino acid ABC transporter, is necessary for disease pathogenesis. Infect. Immun. 77, 3412-3423.

Beasley, F.C., Vines, E.D., Grigg, J.C., Zheng, Q., Liu, S., Lajoie, G.A., Murphy, M.E., Heinrichs, D.E., 2009. Characterization of staphyloferrin A biosynthetic and transport mutants in Staphylococcus aureus. Mol. Microbiol. 72, 947-963.

Begg, S.L., Eijkelkamp, B.A., Luo, Z., Counago, R.M., Morey, J.R., Maher, M.J., Ong, C.L., McEwan, A.G., Kobe, B., O'Mara, M.L., Paton, J.C., McDevitt, C.A., 2015. Dysregulation of transition metal ion homeostasis is the molecular basis for cadmium toxicity in Streptococcus pneumoniae. Nat. Commun. 6, 6418.

Berntsson, R.P., Smits, S.H., Schmitt, L., Slotboom, D.J., Poolman, B., 2010. A structural classification of substrate-binding proteins. FEBS Lett. 584, 2606-2617.

Braun, J.S., Sublett, J.E., Freyer, D., Mitchell, T.J., Cleveland, J.L., Tuomanen, E.I., Weber, J.R., 2002. Pneumococcal pneumolysin and H(2)O(2) mediate brain cell apoptosis during meningitis. J. Clin. Invest. 109, 19-27.

Chen, C.C., Herzberg, O., 2001. Structures of the acyl-enzyme complexes of the Staphylococcus aureus beta-lactamase mutant Glu166Asp:Asn170Gln with benzylpenicillin and cephaloridine. Biochemistry 40, 2351-2358.

Chen, C.C., Smith, T.J., Kapadia, G., Wasch, S., Zawadzke, L.E., Coulson, A., Herzberg, O. 1996. Structure and kinetics of the beta-lactamase mutants S70A and K73H from Staphylococcus aureus PC1. Biochemistry 35, 12251-12258.

Cheng, W., Li, Q., Jiang, Y.L., Zhou, C.Z., Chen, Y., 2013. Structures of Streptococcus pneumoniae PiaA and its complex with ferrichrome reveal insights into the substrate binding and release of high affinity iron transporters. PLoS One 8, e71451.

Counago, R.M., Ween, M.P., Begg, S.L., Bajaj, M., Zuegg, J., O'Mara, M.L., Cooper, M.A., McEwan, A.G., Paton, J.C., Kobe, B., McDevitt, C.A., 2014. Imperfect coordination chemistry facilitates metal ion release in the Psa permease. Nat. Chem. Biol. 10, $35-41$.

Culurgioni, S., Tang, M., Walsh, M.A., 2017a. Structural characterization of the Streptococcus pneumoniae carbohydrate substrate-binding protein SP0092. Acta Crystallogr. F Struct. Biol. Commun. 73, 54-61.

Culurgioni, S., Harris, G., Singh, A.K., King, S.J., Walsh, M.A., 2017b. Structural basis for regulation and specificity of fructooligosaccharide import in Streptococcus pneumoniae. Structure 25, 79-93.

Cundell, D.R., Tuomanen, E.I., 1994. Receptor specificity of adherence of Streptococcus pneumoniae to human type-II pneumocytes and vascular endothelial cells in vitro. Microb. Pathog. 17, 361-374.

Dintilhac, A., Claverys, J.P., 1997. The adc locus, which affects competence for genetic transformation in Streptococcus pneumoniae, encodes an ABC transporter with a putative lipoprotein homologous to a family of streptococcal adhesins. Res. Microbiol. 148, 119-131.

Driessen, A.J., Nouwen, N., 2008. Protein translocation across the bacterial cytoplasmic membrane. Annu. Rev. Biochem. 77, 643-667.

Duane, P.G., Rubins, J.B., Weisel, H.R., Janoff, E.N., 1993. Identification of hydrogen peroxide as a Streptococcus pneumoniae toxin for rat alveolar epithelial cells. Infect. Immun. 61, 4392-4397.

Ezraty, B., Gennaris, A., Barras, F., Collet, J.F., 2017. Oxidative stress, protein damage and repair in bacteria. Nat. Rev. Microbiol. 15, 385-396.

Fanghanel, J., Fischer, G., 2004. Insights into the catalytic mechanism of peptidyl prolyl cis/trans isomerases. Front. Biosci. 9, 3453-3478.

Fischetti, V.A., Pancholi, V., Schneewind, O., 1990. Conservation of a hexapeptide sequence in the anchor region of surface proteins from gram-positive cocci. Mol. Microbiol. 4, 1603-1605.

Flannagan, S.E., Clewell, D.B., 2002. Identification and characterization of genes encoding sex pheromone cAM373 activity in Enterococcus faecalis and Staphylococcus aureus. Mol. Microbiol. 44, 803-817.

Friedman, D.B., Stauff, D.L., Pishchany, G., Whitwell, C.W., Torres, V.J., Skaar, E.P., 2006. Staphylococcus aureus redirects central metabolism to increase iron availability. PLoS Pathog. 2, e87.

Fukami-Kobayashi, K., Tateno, Y., Nishikawa, K., 1999. Domain dislocation: a change of core structure in periplasmic binding proteins in their evolutionary history. J. Mol. Biol. 286, 279-290.

Graham, M.R., Virtaneva, K., Porcella, S.F., Gardner, D.J., Long, R.D., Welty, D.M., Barry, W.T., Johnson, C.A., Parkins, L.D., Wright, F.A., Musser, J.M., 2006. Analysis of the transcriptome of group A Streptococcus in mouse soft tissue infection. Am. J. Pathol. $169,927-942$. 
Gribenko, A., Mosyak, L., Ghosh, S., Parris, K., Svenson, K., Moran, J., Chu, L., Li, S., Liu, T., Woods Jr., V.L., Jansen, K.U., Green, B.A., Anderson, A.S., Matsuka, Y.V., 2013. Three-dimensional structure and biophysical characterization of Staphylococcus aureus cell surface antigen-manganese transporter MntC. J. Mol. Biol. 425, 3429-3445.

Gribenko, A.V., Parris, K., Mosyak, L., Li, S., Handke, L., Hawkins, J.C., Severina, E., Matsuka, Y.V., Anderson, A.S., 2016. High resolution mapping of bactericidal monoclonal antibody binding epitopes on staphylococcus aureus antigen MntC. PLoS Pathog. 12, e1005908.

Grigg, J.C., Vermeiren, C.L., Heinrichs, D.E., Murphy, M.E., 2007. Heme coordination by staphylococcus aureus IsdE. J. Biol. Chem. 282, 28815-28822.

Grigg, J.C., Cheung, J., Heinrichs, D.E., Murphy, M.E., 2010a. Specificity of Staphyloferrin B recognition by the SirA receptor from Staphylococcus aureus. J. Biol. Chem. 285, 34579-34588.

Grigg, J.C., Cooper, J.D., Cheung, J., Heinrichs, D.E., Murphy, M.E., 2010b. The Staphylococcus aureus siderophore receptor HtsA undergoes localized conformational changes to enclose staphyloferrin A in an arginine-rich binding pocket. J. Biol. Chem. 285, 11162-11171.

Hammer, N.D., Skaar, E.P., 2011. Molecular mechanisms of Staphylococcus aureus iron acquisition. Annu. Rev. Microbiol. 65, 129-147.

Heikkinen, O., Seppala, R., Tossavainen, H., Heikkinen, S., Koskela, H., Permi, P., Kilpelainen, I., 2009. Solution structure of the parvulin-type PPIase domain of Staphylococcus aureus PrsA-implications for the catalytic mechanism of parvulins. BMC Struct. Biol. 9, 17.

Heinrichs, J.H., Gatlin, L.E., Kunsch, C., Choi, G.H., Hanson, M.S., 1999. Identification and characterization of SirA, an iron-regulated protein from Staphylococcus aureus. J. Bacteriol. 181, 1436-1443.

Henrissat, B., Deleury, E., Coutinho, P.M., 2002. Glycogen metabolism loss: a common marker of parasitic behaviour in bacteria? Trends Genet. 18, 437-440.

Heras, B., Kurz, M., Jarrott, R., Shouldice, S.R., Frei, P., Robin, G., Cemazar, M., ThonyMeyer, L., Glockshuber, R., Martin, J.L., 2008. Staphylococcus aureus DsbA does not have a destabilizing disulfide: a new paradigm for bacterial oxidative folding. J. Biol. Chem. 283, 4261-4271.

Herzberg, O., Moult, J., 1987. Bacterial resistance to beta-lactam antibiotics: crystal structure of beta-lactamase from Staphylococcus aureus PC1 at 2.5 A resolution. Science 236, 694-701.

Higgins, M.A., Abbott, D.W., Boulanger, M.J., Boraston, A.B., 2009. Blood group antigen recognition by a solute-binding protein from a serotype 3 strain of Streptococcus pneumoniae. J. Mol. Biol. 388, 299-309.

Hoskins, J., Alborn Jr., W.E., Arnold, J., Blaszczak, L.C., Burgett, S., DeHoff, B.S., Estrem, S.T., Fritz, L., Fu, D.J., Fuller, W., Geringer, C., Gilmour, R., Glass, J.S., Khoja, H., Kraft, A.R., Lagace, R.E., LeBlanc, D.J., Lee, L.N., Lefkowitz, E.J., Lu, J., Matsushima, P., McAhren, S.M., McHenney, M., McLeaster, K., Mundy, C.W., Nicas, T.I., Norris, F.H., O'Gara, M., Peery, R.B., Robertson, G.T., Rockey, P., Sun, P.M., Winkler, M.E., Yang, Y., Young-Bellido, M., Zhao, G., Zook, C.A., Baltz, R.H., Jaskunas, S.R., Rosteck Jr., P.R., Skatrud, P.L., Glass, J.I., 2001. Genome of the bacterium Streptococcus pneumoniae strain R6. J. Bacteriol. 183, 5709-5717.

Hutchings, M.I., Palmer, T., Harrington, D.J., Sutcliffe, I.C., 2009. Lipoprotein biogenesis in gram-positive bacteria: knowing when to hold 'em, knowing when to fold 'em. Trends Microbiol. 17, 13-21.

Ilangovan, U., Ton-That, H., Iwahara, J., Schneewind, O., Clubb, R.T., 2001. Structure of sortase, the transpeptidase that anchors proteins to the cell wall of Staphylococcus aureus. Proc. Natl. Acad. Sci. U. S. A. 98, 6056-6061.

Johnston, J.W., Myers, L.E., Ochs, M.M., Benjamin Jr., W.H., Briles, D.E., Hollingshead, S.K., 2004. Lipoprotein PsaA in virulence of Streptococcus pneumoniae: surface accessibility and role in protection from superoxide. Infect. Immun. 72, 5858-5867.

Jousselin, A., Manzano, C., Biette, A., Reed, P., Pinho, M.G., Rosato, A.E., Kelley, W.L., Renzoni, A., 2015. The staphylococcus aureus chaperone PrsA is a new auxiliary factor of oxacillin resistance affecting penicillin-binding protein 2A. Antimicrob. Agents Chemother. 60, 1656-1666.

Khandavilli, S., Homer, K.A., Yuste, J., Basavanna, S., Mitchell, T., Brown, J.S., 2008. Maturation of Streptococcus pneumoniae lipoproteins by a type II signal peptidase is required for $\mathrm{ABC}$ transporter function and full virulence. Mol. Microbiol. 67, $541-557$.

Kohler, S., Voss, F., Gomez Mejia, A., Brown, J.S., Hammerschmidt, S., 2016. Pneumococcal lipoproteins involved in bacterial fitness, virulence, and immune evasion. FEBS Lett. 590, 3820-3839.

Kovacs-Simon, A., Titball, R.W., Michell, S.L., 2011. Lipoproteins of bacterial pathogens. Infect. Immun. 79, 548-561.

Lawrence, M.C., Pilling, P.A., Epa, V.C., Berry, A.M., Ogunniyi, A.D., Paton, J.C., 1998 The crystal structure of pneumococcal surface antigen PsaA reveals a metal-binding site and a novel structure for a putative ABC-type binding protein. Structure 6, 1553-1561.

Lebrette, H., Borezee-Durant, E., Martin, L., Richaud, P., Boeri Erba, E., Cavazza, C., 2015. Novel insights into nickel import in Staphylococcus aureus: the positive role of free histidine and structural characterization of a new thiazolidine-type nickel chelator. Metallomics 7, 613-621.

Loisel, E., Jacquamet, L., Serre, L., Bauvois, C., Ferrer, J.L., Vernet, T., Di Guilmi, A.M., Durmort, C., 2008. AdcAII, a new pneumococcal Zn-binding protein homologous with ABC transporters: biochemical and structural analysis. J. Mol. Biol. 381, 594-606.

Madan Babu, M., Sankaran, K., 2002. DOLOP-database of bacterial lipoproteins. Bioinformatics 18, 641-643.

Manzano, C., Contreras-Martel, C., El Mortaji, L., Izore, T., Fenel, D., Vernet, T., Schoehn, G., Di Guilmi, A.M., Dessen, A., 2008. Sortase-mediated pilus fiber biogenesis in Streptococcus pneumoniae. Structure 16, 1838-1848.
Mao, B., Pear, M.R., McCammon, J.A., Quiocho, F.A., 1982. Hinge-bending in L-arabi nose-binding protein. the venus's-flytrap model. J. Biol. Chem. 257, 1131-1133.

Mariotti, P., Malito, E., Biancucci, M., Lo Surdo, P., Mishra, R.P., Nardi-Dei, V., Savino, S, Nissum, M., Spraggon, G., Grandi, G., Bagnoli, F., Bottomley, M.J., 2013. Structural and functional characterization of the Staphylococcus aureus virulence factor and vaccine candidate FhuD2. Biochem. J 449, 683-693.

McDevitt, C.A., Ogunniyi, A.D., Valkov, E., Lawrence, M.C., Kobe, B., McEwan, A.G., Paton, J.C., 2011. A molecular mechanism for bacterial susceptibility to zinc. PLoS Pathog. 7, e1002357.

Nakayama, H., Kurokawa, K., Lee, B.L., 2012. Lipoproteins in bacteria: structures and biosynthetic pathways. FEBS J. 279, 4247-4268.

Narita, S., Matsuyama, S., Tokuda, H., 2004. Lipoprotein trafficking in Escherichia coli. Arch. Microbiol. 182, 1-6.

Neubauer, H., Pantel, I., Lindgren, P.E., Gotz, F., 1999. Characterization of the molybdate transport system ModABC of Staphylococcus carnosus. Arch. Microbiol. 172, 109-115.

Nguyen, M.T., Gotz, F., 2016. Lipoproteins of gram-positive bacteria: key players in the immune response and virulence. Microbiol. Mol. Biol. Rev. 80, 891-903.

Nguyen, M.T., Kraft, B., Yu, W., Demircioglu, D.D., Hertlein, T., Burian, M., Schmaler, M., Boller, K., Bekeredjian-Ding, I., Ohlsen, K., Schittek, B., Gotz, F., 2015a. Correction the nuSaalpha specific lipoprotein like cluster (lpl) of S. aureus USA300 contributes to immune stimulation and invasion in human cells. PLoS Pathog. 11, e1005189.

Nguyen, M.T., Kraft, B., Yu, W., Demircioglu, D.D., Hertlein, T., Burian, M., Schmaler, M., Boller, K., Bekeredjian-Ding, I., Ohlsen, K., Schittek, B., Gotz, F., 2015b. The nuSaalpha specific lipoprotein like cluster (lpl) of S. aureus USA300 contributes to immune stimulation and invasion in human cells. PLoS Pathog. 11 (e1004984).

Ong, C.L., Potter, A.J., Trappetti, C., Walker, M.J., Jennings, M.P., Paton, J.C., McEwan, A.G., 2013. Interplay between manganese and iron in pneumococcal pathogenesis: role of the orphan response regulator RitR. Infect. Immun. 81, 421-429.

Orihuela, C.J., Mills, J., Robb, C.W., Wilson, C.J., Watson, D.A., Niesel, D.W., 2001. Streptococcus pneumoniae PstS production is phosphate responsive and enhanced during growth in the murine peritoneal cavity. Infect. Immun. 69, 7565-7571.

Oudega, B., Clark, D., Stegehuis, F., Majoor, M.J., Luirink, J., 1993. A lipoprotein signal peptide plus a cysteine residue at the amino-terminal end of the periplasmic protein beta-lactamase is sufficient for its lipid modification, processing and membrane localization in Escherichia coli. FEMS Microbiol. Lett. 108, 353-359.

Podkowa, K.J., Briere, L.A., Heinrichs, D.E., Shilton, B.H., 2014. Crystal and solution structure analysis of FhuD2 from Staphylococcus aureus in multiple unliganded conformations and bound to ferrioxamine-B. Biochemistry 53, 2017-2031.

Potter, A.J., Trappetti, C., Paton, J.C., 2012. Streptococcus pneumoniae uses glutathione to defend against oxidative stress and metal ion toxicity. J. Bacteriol. 194, 6248-6254.

Pribyl, T., Moche, M., Dreisbach, A., Bijlsma, J.J., Saleh, M., Abdullah, M.R., Hecker, M., van Dijl, J.M., Becher, D., Hammerschmidt, S., 2014. Influence of impaired lipoprotein biogenesis on surface and exoproteome of Streptococcus pneumoniae. J. Proteome. Res. 13, 650-667.

Punta, M., Coggill, P.C., Eberhardt, R.Y., Mistry, J., Tate, J., Boursnell, C., Pang, N., Forslund, K., Ceric, G., Clements, J., Heger, A., Holm, L., Sonnhammer, E.L., Eddy, S.R., Bateman, A., Finn, R.D., 2012. The Pfam protein families database. Nucleic Acids Res. 40, D290-301.

Remy, L., Carriere, M., Derre-Bobillot, A., Martini, C., Sanguinetti, M., Borezee-Durant, E., 2013. The Staphylococcus aureus Opp1 ABC transporter imports nickel and cobalt in zinc-depleted conditions and contributes to virulence. Mol. Microbiol. 87, 730-743.

Robb, M., Hobbs, J.K., Woodiga, S.A., Shapiro-Ward, S., Suits, M.D., McGregor, N., Brumer, H., Yesilkaya, H., King, S.J., Boraston, A.B., 2017. Molecular characterization of N-glycan degradation and transport in streptococcus pneumoniae and its contribution to virulence. PLoS Pathog. 13, e1006090.

Saleh, M., Bartual, S.G., Abdullah, M.R., Jensch, I., Asmat, T.M., Petruschka, L., Pribyl, T., Gellert, M., Lillig, C.H., Antelmann, H., Hermoso, J.A., Hammerschmidt, S., 2013. Molecular architecture of Streptococcus pneumoniae surface thioredoxin-fold lipoproteins crucial for extracellular oxidative stress resistance and maintenance of virulence. EMBO Mol. Med. 5, 1852-1870.

Sankaran, K., Wu, H.C., 1994. Lipid modification of bacterial prolipoprotein: transfer of diacylglyceryl moiety from phosphatidylglycerol. J. Biol. Chem. 269, 19701-19706.

Scheepers, G.H., Lycklama, A.N.J.A., Poolman, B., 2016. An updated structural classification of substrate-binding proteins. FEBS Lett. 590, 4393-4401.

Schluepen, C., Malito, E., Marongiu, A., Schirle, M., McWhinnie, E., Lo Surdo, P., Biancucci, M., Falugi, F., Nardi-Dei, V., Marchi, S., Fontana, M.R., Lombardi, B., De Falco, M.G., Rinaudo, C.D., Spraggon, G., Nissum, M., Bagnoli, F., Grandi, G., Bottomley, M.J., Liberatori, S., 2013. Mining the bacterial unknown proteome: identification and characterization of a novel family of highly conserved protective antigens in Staphylococcus aureus. Biochem. J. 455, 273-284.

Schmaler, M., Jann, N.J., Ferracin, F., Landolt, L.Z., Biswas, L., Gotz, F., Landmann, R., 2009. Lipoproteins in Staphylococcus aureus mediate inflammation by TLR2 and iron-dependent growth in vivo. J. Immunol. 182, 7110-7118.

Schneewind, O., Model, P., Fischetti, V.A., 1992. Sorting of protein A to the staphylococcal cell wall. Cell 70, 267-281.

Sebulsky, M.T., Heinrichs, D.E., 2001. Identification and characterization of fhuD1 and fhuD2, two genes involved in iron-hydroxamate uptake in Staphylococcus aureus. J. Bacteriol. 183, 4994-5000.

Sebulsky, M.T., Speziali, C.D., Shilton, B.H., Edgell, D.R., Heinrichs, D.E., 2004. FhuD1, a ferric hydroxamate-binding lipoprotein in Staphylococcus aureus: a case of gene duplication and lateral transfer. J. Biol. Chem. 279, 53152-53159.

Selva, L., Viana, D., Regev-Yochay, G., Trzcinski, K., Corpa, J.M., Lasa, I., Novick, R.P., Penades, J.R., 2009. Killing niche competitors by remote-control bacteriophage induction. Proc. Natl. Acad. Sci. U. S. A. 106, 1234-1238. 
Shahmirzadi, S.V., Nguyen, M.T., Gotz, F., 2016. Evaluation of staphylococcus aureus lipoproteins: role in nutritional acquisition and pathogenicity. Front. Microbiol. 7, 1404.

Tettelin, H., Nelson, K.E., Paulsen, I.T., Eisen, J.A., Read, T.D., Peterson, S., Heidelberg, J., DeBoy, R.T., Haft, D.H., Dodson, R.J., Durkin, A.S., Gwinn, M., Kolonay, J.F., Nelson, W.C., Peterson, J.D., Umayam, L.A., White, O., Salzberg, S.L., Lewis, M.R., Radune, D., Holtzapple, E., Khouri, H., Wolf, A.M., Utterback, T.R., Hansen, C.L., McDonald, L.A., Feldblyum, T.V., Angiuoli, S., Dickinson, T., Hickey, E.K., Holt, I.E., Loftus, B.J., Yang, F., Smith, H.O., Venter, J.C., Dougherty, B.A., Morrison, D.A., Hollingshead, S.K., Fraser, C.M., 2001. Complete genome sequence of a virulent isolate of Streptococcus pneumoniae. Science 293, 498-506.

Tseng, H.J., McEwan, A.G., Paton, J.C., Jennings, M.P., 2002. Virulence of Streptococcus pneumoniae: psaA mutants are hypersensitive to oxidative stress. Infect. Immun. 70, 1635-1639.

Vitikainen, M., Lappalainen, I., Seppala, R., Antelmann, H., Boer, H., Taira, S., Savilahti, H., Hecker, M., Vihinen, M., Sarvas, M., Kontinen, V.P., 2004. Structure-function analysis of PrsA reveals roles for the parvulin-like and flanking N- and C-terminal domains in protein folding and secretion in Bacillus subtilis. J. Biol. Chem. 279, 19302-19314.

Williams, W.A., Zhang, R.G., Zhou, M., Joachimiak, G., Gornicki, P., Missiakas, D., Joachimiak, A., 2004. The membrane-associated lipoprotein-9 GmpC from Staphylococcus aureus binds the dipeptide GlyMet via side chain interactions. Biochemistry 43, 16193-16202.

Yesilkaya, H., Andisi, V.F., Andrew, P.W., Bijlsma, J.J., 2013. Streptococcus pneumoniae and reactive oxygen species: an unusual approach to living with radicals. Trends Microbiol. 21, 187-195.

Zheng, J.J., Sinha, D., Wayne, K.J., Winkler, M.E., 2016. Physiological roles of the dual phosphate transporter systems in low and high phosphate conditions and in capsule maintenance of streptococcus pneumoniae D39. Front. Cell. Infect. Microbiol. 6, 63.

Zong, Y., Bice, T.W., Ton-That, H., Schneewind, O., Narayana, S.V., 2004. Crystal structures of Staphylococcus aureus sortase A and its substrate complex. J. Biol. Chem. 279, 31383-31389. 